Marine Georesources and Geotechnology

April 2001; 19(2) : 107 - 133

http://dx.doi.org/10.1080/10641190120611

(c) 2001 Taylor \& Francis
Archimer http://www.ifremer.fr/docelec/ Archive Institutionnelle de l'Ifremer

The original publication is available at http://www.tandf.co.uk/journals/

\title{
Evaluation of the Risk of Marine Slope Instability: A Pseudo-3D Approach for Application to Large Areas
}

\author{
Nabil Sultan*, Pierre Cochonat, Jean François Bourillet, Florence Cayocca
}

IFREMER, Géosciences Marines, Laboratoire Environnements Sédimentaires, 29280 PLOUZANE

*: Corresponding author : Tel: 02.98.22.42.59 Fax: 02.98.22.45.70 E-mail: nabil.sultan@ifremer.fr

\begin{abstract}
This paper presents a methodology developed to evaluate the instability of submarine slopes that extends over a large area. Special attention was paid to 1) the complex geometry (bathymetry) and the expanse of the slope, 2) the heterogeneity of the sediment and 3) the distribution of the pore pressure. The safety factor was considered as a spatially varying quantity. The General Formulation (GLE - Fredlund and Krahn 1977), which fully satisfies equilibrium conditions, was used for evaluating the stability of the marine slope. The submarine slope failure, which occurred on October 16th 1979 during the construction of new Nice airport, was studied in order to test the developed model. Geotechnical parameters were taken from experimental tests carried out by IFREMER on 19 cores extracted at different depths (from $27 \mathrm{~m}$ to $1300 \mathrm{~m}$ ) (Cochonat et al. 1993 and Mulder et al. 1994). Many scenarios were proposed in order to explain the cause of the Nice slope failure (Habib 1994). In this paper, two of those scenarios were tested. Simulation results are presented and discussed.
\end{abstract}

Keywords: failure, finite difference, finite element, marine sediment, safety factor, slope stability, shear strength 


\section{INTRODUCTION:}

Increased attention has been paid to submarine slope instability in the last 3 decades. Industrial and scientific concern have instigated numerous studies regarding design of marine constructions, offshore structures and pipelines, and comprehension of the continental slope failure and depositional processes (see for instance Mulder and Cochonat 1996). Data are now available on instability of submarine slopes in different environments ranging from shallow-water and near-shore areas to continental slopes and Deep Ocean. Most often, slumps involve a large volume of material (Magdalena River delta $310^{8} \mathrm{~m}^{3}$; Suva, Fiji $1.510^{8} \mathrm{~m}^{3}$; Valdez, Alaska $7.510^{7} \mathrm{~m}^{3}$; Orkdals Fjord $10^{7} \mathrm{~m}^{3}$; Sagami Wan $710^{10} \mathrm{~m}^{3}$ from Morgenstern (1967) - Storrega $5.610^{12} \mathrm{~m}^{3}$ from Bugge et al. (1987)); as opposed to on-shore landslides, submarine slides can take place on very gentle slopes, even less than one degree. For example, the slump of the Mississippi River delta occurred on a slope with an angle of only $0.5^{\circ}$. Unfortunately, while special attention has been focused on the description of new sites of submarine slides (Coleman and Garrison 1977, Embley and Jacobi 1977, Hampton and Bouma 1977, McGregor 1977, Embley 1980, Orren and Hamilton 1998, Berné et al. 1998), little attention has been paid to the comprehension of the processes at the origin of the slope instabilities.

This paper describes a new methodology developed for evaluating the risk of marine slope instability. The instability of submarine slopes may vary significantly with the extent of the slope and the complexity of the bathymetry. In addition, the heterogeneity of the hydro-mechanical characteristics of the sediment can greatly modify slope flow fields, effective-stress fields, and slope stability. Consequently, it was appropriate to evaluate the stability as a spatially varying quantity. Moreover, 
marine slope instability can be an important mechanism for sediment transport and deposition. Therefore, it was fundamental to identify the right geometry of the failure surface in order to simulate correctly the sediment transport and the turbidity currents.

\section{NICE SLOPE: GEOLOGICAL SETTING AND GEOTECHNICAL CHARACTERISATION.}

The continental slope off the coast of Nice is characterised by a very narrow shelf generally less than 2 kilometres wide. The $1000 \mathrm{~m}$ isobath lies only $5 \mathrm{~km}$ from the coastline (Savoye et al. 1989) and the steep slope is strongly eroded and dissected by several canyons and gullies, of which the Var and the Paillon canyons (Figure 1) are the most important features $\left(>10^{\circ}\right.$ gradient slope and $>2000 \mathrm{~m}$ deep) (Bourillet 1991). Both canyons are directly connected to the Var and Paillon rivers and coalesce downslope to form the Var sedimentary system.

The Var sedimentary system covers a surface area of $16200 \mathrm{~km}^{2}$ extending from the coast of the French Riviera between Nice and Monaco to the base of the northern continental slope of Corsica. It is the most extensive detrital province of the Ligurian Sea. The Var sedimentary system was deposited during the Pliocene and Quaternary. After the Messinian low stage of the late Miocene, when sea level was lowered about $1200 \mathrm{~m}$ in the area (Piper and Savoye, 1991), the return of open-marine conditions in the Pliocene and the Quaternary resulted in deposition of a 600-1000 m thick sequence of marls and conglomerates on the continental slope. Quaternary uplift and sediment supply from the glaciated Alps resulted in supply of coarse sediments to the fan by the braided Var River throughout the Quaternary even at sea level highstands such as at present. 
Sediment deposition in the upper continental slope in the Baie des Anges is strongly linked to fluvial input from the Var river, the Paillon River being only a minor source. The upper slope is an area experiencing active sediment transport, where at least three major types of sediment transfer processes are identified (Mulder et al. 1996): 1) hyperpycnal turbid plumes, 2) surge-like turbidity currents generated by shallow failure and 3) large earthquake-triggered slides.

The submarine slope failure, which occurred on October 1979 during the construction of the new Nice airport was attributed to the effect of a mass-wasting process that generated a turbidity current in the Var canyon (Auffret et al. 1982). It can be considered as a typical shallow failure as has been recently surveyed by EM 1000 mapping (Bourillet et al, 1992). Several studies of the area had been carried out following the event, particularly multibeam echosounder, seismic and side-scan sonar surveys (Genesseaux et al 1980, Pautot et al., 1981, Malinverno et al., 1988). Several sediment facies were differentiated and classified by laboratory-determined mass physical and geotechnical properties (including the undrained shear strength $\mathrm{Su}$ ) of nineteen gravity core samples of 2 to $7 \mathrm{~m}$ length (Cochonat et al., 1993). This classification was used in order to produce a geotechnical map of the surficial sediments in the area. Based on the Skempton (1954) equation, the overconsolidation ratio OCR was calculated from the plasticity index Ip and the density of the soil $\gamma^{\prime}$ $\left(O C R=\frac{\sigma_{p}^{\prime}}{\sigma_{v}^{\prime}}=\frac{f(S u, I p)}{\int_{0}^{z} \gamma^{\prime}(z) d z}\right)$. Therefore, it was possible to classify the sediments into four main types (Mulder et al. 1994):

Type A: underconsolidated sediments: $S_{u}=1.35 z$;

Type B: normally-consolidated sediments: $S_{u}=1.2 z+5$; 
Type C: Slightly overconsolidated sediments: $S_{u}=2.5 z+5$;

Type D: overconsolidated sediments: $S_{u}=12 z+7$.

with $S_{u}$ in $\mathrm{kPa}$ and $z$ in meters.

The geographical distribution of these four geotechnical sediment types is illustrated in Figure 2. More details on this classification are presented in Cochonat et al. (1993) and Mulder et al. (1994). This study only considers the area where the geotechnical data are available from Cochonat et al. (1993) (Figure 3). The average slope gradient is $13^{\circ}$ but values ranging up to $20^{\circ}-30^{\circ}$ are common (Figure 3 ).

\section{METHODOLOGY}

The complex bathymetry and the large extent of the submarine zone under investigation make it impossible to carry out a complete 3-D slope stability analysis. The main objective of this work is to perform a two-dimensional slope stability analysis in vertical cross-sections and to extend it to the three-dimensional area. The complex geometry of the slope, the heterogeneity of the sediment and the pore pressure effect on the slope stability must be taken into account. This is possible by performing the following phases:

- drawing a series of cross-sections across the area;

- taking into account the heterogeneity of the marine sediment by affecting the relevant geotechnical properties (Figure 2) to the sediment according to its nature (undrained shear strength $S_{u}$, cohesion $c^{\prime}$, internal friction angle $\varphi^{\prime}$, hydraulic conductivity $c_{v}$, permeability $k, \ldots)$;

- calculating the pore pressure in each node from initial and boundary conditions for transient state or steady-state regime; 
- determining all the possible concave slip surfaces (circle or non-circle);

- calculating the safety factor on all the selected slip surfaces;

- searching for the critical slip surface where the safety factor is minimal;

- generating the safety factor and the slip surface to the three dimensional area.

\subsection{CROSS-SECTION AND GRID GENERATION}

The first step to carry out in this slope stability analysis is to draw a series of cross-sections across the bathymetry map. For that purpose, the slope angle given by equation 1 is calculated at each grid node of the bathymetry (Figure 3 ).

$$
\alpha_{i, j}=A \tan \sqrt{\left[\frac{z_{i, j+1}-z_{i, j-1}}{2 \Delta x}\right]^{2}+\left[\frac{z_{i+1, j}-z_{i-1, j}}{2 \Delta y}\right]^{2}}
$$

where $z$ is the elevation and $\Delta x$ and $\Delta y$ are the grid increments (Figure 4).

An automatic search of the azimuth direction is done for each node with a value of $\alpha$ greater than a critical angle $\alpha_{c}$. The value of $\alpha_{c}$ depends on the bathymetry and is defined in order to scan the whole zone. A vertical cross-section is performed along the azimuth angle $\beta$ (eq. 2) through each of these nodes, across the whole area under investigation (Figure 5).

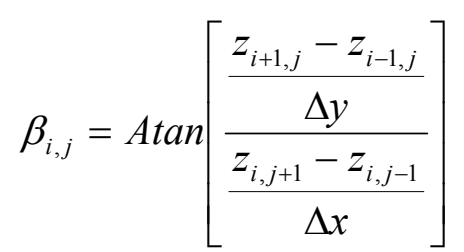

Each section is analysed independently of the others. The computational domain of each vertical cross-section is limited by two surfaces: while the upper surface follows the 
bathymetry, the lower surface is determined from the stratigraphy, material properties and boundary and initial conditions.

The domain is described by an irregular $2 \mathrm{D}$ rectangular grid to take into account the complex geometry and the multiple materials and properties. Each interior node is connected to its four neighbouring nodes, however these connections are not necessarily orthogonal (Figure 6).

Special attention is paid to the grid size (defined by $\Delta x$ and $\Delta z$ ), which influences the accuracy of the simulation results.

In order to take into account the hydro-mechanical heterogeneity of the soil, the geotechnical parameters (undrained shear strength $S_{u}$, cohesion $c^{\prime}$, internal friction angle $\varphi^{\prime}$, hydraulic conductivity $c_{v}$, permeability $k$, etc.) are affected to each node (Figure 6).

\subsection{DETERMINATION OF THE PORE PRESSURE}

Pore pressure is an essential parameter in the marine slope stability analysis. Impermeable sediment can impede water flow and generate a build up of pore pressure and consequently an unstable slope. The distribution of the pore pressure in a steadystate regime is governed by Laplace equation. For the two-dimensional steady-state flow, Laplace's equation is expressed by:

$$
\nabla^{2} u(x, z)=\frac{\partial^{2} u(x, z)}{\partial x^{2}}+\frac{\partial^{2} u(x, z)}{\partial z^{2}}=0
$$

The solution of equation 3 is determined by using the finite difference method. Equation 3 then yields:

$$
u_{i, j}=\frac{\Delta z^{2}\left[u_{i-1, j}+u_{i+1, j}\right]+\Delta x^{2}\left[u_{i, j-1}+u_{i, j+1}\right]}{2\left[\Delta x^{2}+\Delta z^{2}\right]}
$$


For a one dimensional steady state flow, and in homogenous sediment, the pore pressure profile is linear.

For transient flow, the pore water distribution is calculated from the following equation:

$$
c_{v}\left[\frac{\partial^{2} u(x, z, t)}{\partial x^{2}}+\frac{\partial^{2} u(x, z, t)}{\partial z^{2}}\right]=\frac{\partial u(x, z, t)}{\partial t}
$$

where $c v$ is the hydraulic conductivity.

For a two dimensional transient flow, the solution of equation 5 is given by the explicit finite difference approximation, and equation 5 can be expressed by:

$$
\frac{u_{i+1, j}^{n}-2 u_{i, j}^{n}+u_{i-1, j}^{n}}{[\Delta x]^{2}}+\frac{u_{i, j+1}^{n}-2 u_{i, j}^{n}+u_{i, j-1}^{n}}{[\Delta z]^{2}}=\frac{1}{c_{v}} \frac{u_{i j}^{n+1}-u_{i j}^{n}}{\Delta t}
$$

where $u^{n}$ and $u^{n+1}$ correspond respectively to the pore water distribution at time $t$ and time $t+\Delta t$.

Thus, the pore pressure at the time $t+\Delta t$ is given by:

$$
u_{i j}^{n+1}=u_{i j}^{n}+c_{v} \Delta t\left[\frac{u_{i+1, j}^{n}-2 u_{i, j}^{n}+u_{i-1, j}^{n}}{[\Delta x]^{2}}+\frac{u_{i, j+1}^{n}-2 u_{i, j}^{n}+u_{i, j-1}^{n}}{[\Delta z]^{2}}\right]
$$

where the pore pressure at the time $t$ is considered as known.

For a steady state or transient regime and based on the boundary and initial conditions, equations 4 or 7 are used to calculate the pore pressure in each node. The heterogeneity in hydraulic conductivity influences the water flow fields. Consequently, the effective-stress field is modified. Low hydraulic conductivity materials that impede downslope water flow can create unstable areas with locally elevated pore-water pressures. For a vertical hydraulic gradient $\vec{i}$ (eq. 8) greater than the critical hydraulic 
gradient $\left(i_{c}=\frac{\gamma^{\prime}}{\gamma_{w}}\right.$ for vertical flow), the sediment may be moved by the escaping fluid and it could generate the formation of a seabed pockmarks.

$$
\bar{i}=-\overline{\operatorname{grad}}\left[\frac{u}{\gamma_{w}}+z\right]
$$

where $\frac{u}{\gamma_{w}}$ is the head pressure and $\mathrm{z}$ the elevation.

Once the pockmarks are created, the safety factors of the near slopes are reduced and the development of progressive failure slides can be accelerated.

\subsection{SEARCH SCHEME OF THE GENERALISED SLIP SURFACE}

Different methods (limit equilibrium method, limit analysis method, energetic method and finite element method) were proposed in the literature to solve the problem of slope stability analysis. However, the limit equilibrium methods are commonly used because of the simplicity with which complex geometry, soil heterogeneity and pore water pressure conditions can be taken into account. These methods require to postulate a collapse mechanism by which failure can occur. By examining a number of different mechanisms, the critical one where the safety factor is minimal is found. Since no restriction on the shape of the slip surface is considered, the solution obtained from the limit-equilibrium method is not rigorous, because neither static nor kinematic admissibility conditions are satisfied (Chen and Giger 1971, Chen 1975, Karal 1977, Michalowski 1995 among others).

The validity of the limit equilibrium method is discussed hereafter in order to justify our search scheme of the slip surface. 
In the limit equilibrium method the soil obeys the Mohr-Coulomb criterion; the yield function in the $\tau$ (shear stress) - $\sigma^{\prime}$ (normal effective stress) plane is given by equation 9 :

$$
f: \tau-c^{\prime}-\sigma^{\prime} \tan \varphi^{\prime}=0
$$

where $c^{\prime}$ and $\varphi^{\prime}$ are respectively the cohesion and the internal friction angle of the soil.

In the Mohr-Coulomb constitutive model, the soil is considered to have an elastic perfectly plastic behaviour. The flow rule is associated to the Mohr-Coulomb yield condition and the plastic potential $g$ coincides with the yield function $f$. Therefore, and according to equation 10, the total strain increment is normal to the yield curve $f$ (Figure 7).

$$
d \underline{\underline{\varepsilon}}^{p}=\lambda \frac{\partial g}{\partial \underline{\underline{\sigma^{\prime}}}}=\lambda \frac{\partial f}{\partial \underline{\underline{\sigma^{\prime}}}}
$$

where $\lambda$ is the plastic multiplier

This associative flow rule requires that the plastic strain increment be inclined to the failure surface at an angle $\varphi^{\prime}$ (Figure 7). Consequently, the admissible failure modes associated with slice analysis are restricted.

For translational collapse mechanisms, the failure surface may be of arbitrary shape provided that the velocity of a slice is inclined to the slip surface at an angle $\varphi^{\prime}$ (Figure 7). However, the rigid rotational mechanism is admissible only if the failure surface is a log-spiral shape (Chen 1971) expressed by the following equation:

$$
R=R_{0} \exp \left(\left(\theta-\theta_{0}\right) \tan \varphi^{\prime}\right)
$$

where $R$ is the radius of the spiral related to the inclination $\theta$ of the failure surface, and $R_{0}$ and $\theta_{0}$ are the initial values (Figure 7). 
Different authors (Taylor 1948 and Chen 1975), Nash (1987) have examined the accuracy of the limit equilibrium slope stability analysis. For different failure surfaces (slices, circles and log-spirals), the limit equilibrium method and the limit analysis method exhibited a difference less than $5 \%$ (Figure 8 ). One can conclude from these results that although limit-equilibrium analysis causes significant errors regarding both kinematic and static admissibility, the limit equilibrium analysis does not involve large errors in the computed values for the safety factor.

From the above arguments, we opted for the search of an arbitrary shape failure surface. Thus, all the possible failure surfaces in a vertical cross-section are automatically generated (Figure 9). However, in order to obtain a concave failure surface, the different base sections of the slip surface must verify the following condition (Figure 9):

$$
\alpha_{1} \leq \ldots . \leq \alpha_{i} \leq \ldots \ldots \leq \alpha_{n} \leq 90^{\circ}
$$

\subsection{CALCULATION OF THE SAFETY FACTOR IN 2D}

The volume above each of the assumed slip surfaces is divided into vertical slices. The geometry of each slice is characterised by the length of the base $l$, the inclination angle of the base $\alpha$ and the length of the interface $t$ (Figure 10).

The forces acting on a typical slice are shown in Figure 10 where:

$W$ is the weight of the slice;

$T$ is the shear force on the base;

$P$ is the normal force on the base;

$U$ is the water pressure force on the base;

$X$ is the vertical side force 
$E$ is the horizontal side force

All limit equilibrium methods of slope stability analysis use the following definition of the factor of safety (FOS) (Duncan 1996):

$$
F O S=\frac{\text { Shear strength of soil (resisting force) }}{\text { Shear stress required for equilibrium (driving force) }}
$$

In this study, we have adopted the General Formulation (GLE - Fredlund and Krahn 1977), which fully satisfies the equilibrium. Failure is assumed to occur by sliding of the soil along a non-circular slip surface.

By examining overall moment equilibrium about an assumed centre of rotation and overall force equilibrium, two different expressions are obtained for the factor of safety, respectively $F O S_{m}$ (for moment equilibrium) (eq. 13) and $F O S_{f}$ (for force equilibrium) (eq. 14).

$$
\begin{aligned}
F O S_{m} & =\frac{\sum\left[c^{\prime} l+(P-U) \tan \varphi^{\prime}\right] R}{\sum(W d-P f)} \\
F O S_{f} & =\frac{\sum\left(c^{\prime} l+(P-U) \tan \varphi^{\prime}\right) \cos \alpha}{\sum P \sin \alpha}
\end{aligned}
$$

where $l, R, f$ and $d$ are given in Figure 10 .

The normal force $P$ is given by the following equation

$$
P=\frac{\left[W-\left(X_{R}-X_{l}\right)-\frac{1}{F O S_{m, f}}\left(c^{\prime} l \sin \alpha-U \tan \varphi^{\prime} \sin \alpha\right)\right]}{m_{\alpha}}
$$

with

$$
m_{\alpha}=\cos \alpha\left(1+\tan \alpha \frac{\tan \varphi^{\prime}}{F O S_{m, f}}\right)
$$


Since the forces involved in equilibrium methods are statically indeterminate (Table 1.), all methods make assumptions to balance the number of equilibrium equations $(5 n)$ and the number of unknowns $(6 n-2)$ in the problem (Espinoza et al. 1992). Various hypotheses have been proposed to provide the additional $n$ - 2 relationships needed to solve the system of equations. Among the assumptions made about interslice forces, Bishop (1955) proposed the following relation:

$$
X_{R}-X_{l}=0
$$

Morgenstern and Price (1965) proposed a relation between interslice forces inclination and the lateral distance $\mathrm{x}$ :

$$
\frac{X}{E}=\lambda f(x)
$$

Spencer (1967) proposed a constant inclination of the interslice forces

$$
\frac{X}{E}=\text { constant }
$$

Results from Espinoza et al. (1992) showed that the variation in the value of the factor of safety due to the assumptions of Spencer or Morgenstern and Price concerning the internal forces is minimal and there is a marginal increase in accuracy with increasing sophistication as one goes from Spencer to Morgenstern and Price methods. Therefore, we have adopted the Spencer assumption of a constant inclination of the interslice force (eq. 19). Since the safety factor cannot be calculated directly from equations 13 through 16 , the solution is determined by two series of iterative numerical procedure. The first iterative procedure is used to calculate $F O S_{m}$ and $F O S_{f}$, while the second iterative procedure is used to find the constant of equation 20 in order to obtain $F O S_{m}$ equal to $F O S_{f}$ for the same failure surface. 
In a vertical cross-section, each node often belongs to several slip surfaces for each of which a safety factor is computed. The minimal of these safety factors $(F O S)$ is affected to each node and a map of equal values of FOS can be plotted over the whole vertical cross-section (Figure 11).

\subsection{Validation of the used methodology}

\subsubsection{Validation of the safety factor}

Figure 11 shows the equal-values of the factor of safety determined by using the above methodology for undrained failure condition. Two calculations were carried out: 1) for a slope of $45^{\circ}$ and a uniform soil (Figure 11-a) and 2) for the same slope angle with a heterogeneous soil including a weak clay layer (Figure 11-b).

In the first case, the security number $\left(\frac{\gamma H}{C}\right.$, where $\gamma$ is the soil density and $H$ is the slope height) corresponding to the critical $F O S(=1)$ is found equal to 5.88 (Table 2). In the second case, and for the same security number, the safety factor is found equal to 0.64 (Figure 11-b). The shape of the failure surfaces defined by a FOS less than 1 varies between the two calculation cases. In the first case (uniform soil), the shape of the failure surface is quasi-circular while in the second one (weak clay layer) the shape is arbitrary and it generally reaches the weak clay layer.

In order to validate this new methodology in drained and undrained conditions, two other calculations were carried out for a slope of $30^{\circ}$. The safety factor was calculated under drained condition and undrained condition $\left(\varphi^{\prime}=0\right)$. Calculation results are presented in Table 2 and Figure 12. Comparison between the safety factor obtained from this study and the results given by Nash (1987) shows a tiny difference between limit equilibrium method with log-spiral failure surface and the limit equilibrium 
method with arbitrary failure surface, which validates the safety factor obtained by the methodology developed in this work.

\subsubsection{Validation of the Shape of the Failure Surface}

In addition to the safety factor, the shape of the failure surface is a significant element in the study of marine slope instability. Indeed, the shape of the failure surface and the volume of the soil involved must be given for the problems of sediment transport and turbidity current. For this reason, it was essential to validate the shape of the failure surface identified by this new methodology. The finite element method enables us to identify a failure surface, which approaches the theoretical surface. Therefore, the shape of the failure surfaces in the two case studies of Figure 11 is determined by using the finite element method. The soil is considered as a Mohr-Coulomb elastic perfectly plastic material. The yield curve $f$ is defined by the following expression:

$$
f=p \sin \varphi+q\left(\frac{\cos \theta}{\sqrt{3}}-\frac{\sin \theta \sin \varphi}{3}\right)-c \cos \varphi
$$

Where $p, q$ et $\theta$ are respectively the first, second and third stress invariants

The calculation is carried out under the hypothesis of plane deformation. In this work, the visco-plastic strain method (Zienkiewic and Cormeau (1974)) where the yield point can be at the outside of the yield curve for finite periods is used ( $\mathrm{f}>0)$. In this method, the plastic strains are replaced by visco-plastic strains proportional to the value of the yield curve $f$.

The two cases of Figure 11 were studied by using the finite element method. In Figure 13-a is presented the used mesh (8-node quadrilateral elements). The determination of the safety factor by using the finite element method consists in calculating the maximum displacement for various values of the factor of safety FOS with which the 
values of $c$ and $\varphi$ are divided. In equation 20,c and $\varphi$ are respectively replaced by $c / F O S$ and $\varphi / F O S$. The value of FOS corresponding to a sudden increase in displacement is considered as the safety factor. The failure surface is considered as the area where the yield function is positive (Figure 13-b). Comparison between the failure surface determined with the limit equilibrium method (Figure 11-a) and the one determined with the finite element method (Figure 13-b) shows a good agreement between the two methods. The displacement vectors presented in Figure 13-c confirm the rotation mechanism of the soil above the failure surface. Comparison between the shapes of the failure surface obtained with the finite element method (Figure 14-a) and with the limit equilibrium method (Figure 11-b) for the slope with the weak clay layer shows once again the good agreement between the two methods. The displacement field of the soil above the failure surface presented in Figure 14-b shows a combination between rotation and translation mechanisms.

The use of the finite element method to identify the shape of the failure surface was useful to validate the shape identified with the limit equilibrium method with arbitrary shape of failure surface.

In Figure 15 is presented the FOS values calculated with the finite element method and corresponding to the two cases of Figure 11. The value of FOS of 0.98 for the uniform soil and 0.7 for the slope with the weak clay layer are comparable with the values found with the limit equilibrium method (Figure 11). The use of the finite element method for the submarine slopes being difficult to implement, we can conclude that the use of the limit equilibrium method with an arbitrary shape surface is satisfactory for the determination of the safety factor and the form of the failure surface. However, for 
applications where the determination of the displacement field is necessary, it is essential to use the finite element method.

\section{COMPUTATION OF THE SAFETY FACTORS OF THE NICE SLOPE}

In order to test the developed model, we applied it to the Nice slope. Actually, several works were carried out in order to understand the origin of the submarine slope failure, which occurred on October $16^{\text {th }} 1979$ during the extention of Nice new airport. Thus, a number of results were available which were useful to our study; in particular the bathymetry data and the geotechnical test results (Pautot et al. 1981, Bourillet 1991, Cochonat et al. 1993 and Mulder et al. 1994).

However, it is important to mention that the geotechnical parameters used in the calculation were taken from the tests carried out on cores extracted from the post-failure Nice slope. Hence, the geotechnical parameters correspond to the sediments, which have not failed. In addition, the bathymetry presented in Figure 1 is a compilation of pre-failure data for depths ranging from 0 to $150 \mathrm{~m}$ and post-failure data for the deeper part.

In the lack of relevant pre-failure bathymetry data and geotechnical characteristics, it is impossible to identify the origin of the Nice slope failure of 1979. Therefore, the results obtained from the following safety factors calculations are subject to much reserve and cannot be considered to explain the origin of the Nice slope failure. However, a low local safety factor can be very helpful in understanding the various factors that affect the stability and it can be used as an indicator for the high-risk zones.

The geotechnical parameters identified from experimental tests on 19 cores were interpolated over the whole Nice slope area $\left(\sim 30 \mathrm{~km}^{2}\right)$. Geotechnical parameters are 
affected to the grid nodes according to the classification carried out by Cochonat et al. (1993) (Figure 2).

\subsection{INFINITE SLOPE}

Despite the results from literature showing that slope failures can be of both translational and rotational types (see for instance Booth and O'Leary 1991), the infinite slope method is usually used in the study of marine slope stability. The safety factor for infinite slope and under undrained condition is calculated according to the following equation:

$$
F O S=\frac{S_{u}}{\gamma^{\prime} z_{c} \sin \alpha \cos \alpha}
$$

where $\alpha$ is the slope angle and $z_{c}$ is a critical depth (Figure 16) at which the factor of safety is calculated. For an irregular bathymetry, the slope angle $\alpha$ is often taken as the mean value over the slope profile. However, Mulder et al. (1994) proposed to consider the slope angle as a local variable and to calculate the safety factor at each node using equation 21 .

The factors of safety of the Nice slope were computed using Mulder's method for undrained condition. The calculation was carried out for a critical depth $z_{c}$ of $2 \mathrm{~m}$ for the whole area. We considered the geographical distribution of the undrained shear strength profiles shown in Figure 2.

Figure 17 displays the safety factors in the zone defined in Figure 3. Comparison between the slope angle (Figure 3) and the safety factor shows clearly that the slope angle is the dominant parameter in the calculation of the safety factor. The subdivision of the zone into three sectors corresponding to the under-consolidated sediment, normally consolidated and over-consolidated has a secondary effect. The safety factor 
presented in Figure 16 corresponds to a critical depth $\left(z_{c}\right)$ of $3 \mathrm{~m}$. The failure condition is reached $(F O S<1)$ in a local section of the under-consolidated sediment Figure 17.

Despite the simplicity and the rapidity of Mulder's method to determine the safety factor map for a considered area, attention should be paid to some questionable points:

- for a vertical cross-section, the slip failure occurs along a constant depth $z_{c}$ which in some cases implies a convex slip surface (Figure 16);

- for a constant critical depth $z_{c}$, the shape of the slip surface is no more a shape of an usual infinite slope failure surface and the use of equation 21 becomes somewhat doubtful. Indeed, the infinite slope is assembled by an important number of finite slopes where the internal forces between successive finite slopes (Figure 16) can not often be neglected as in the case of infinite slope stability;

- the calculation is carried out on a small local scale, the slope angle is calculated from the surrounding four nodes (Figure 4). For a corresponding elevation of the four nodes, the safety factor becomes very large (Figure 16).

\subsection{GENERAL SLIP SURFACE}

\subsubsection{Stability under static gravitational loading}

Several observations of the sea bottoms have shown that the slides can be carried out by rotation of the mass sediment (see for instance Almagor and Wisman 1977, Booth and O'Leary 1991 and Orren and Hamilton 1998). In order to determine the potential failure surfaces of the area, the new methodology developed in this work was applied to the Nice slope. For a critical angle $\alpha_{c}$ of $27^{\circ}, 2209$ automatic cross-sections were performed in order to scan the whole zone (Figure 5). The thickness of the vertical cross-sections was taken equal to $50 \mathrm{~m}$. About 600 possible failure surfaces were generated by cross- 
section. The calculation was carried out under gravitational loading and for undrained condition. All the calculation steps previously described were performed and the safety factor was determined at each node.

The map of the safety factor presented in Figure 18 shows that the failure condition is reached at several local sections at different depths and the slope angle is no more the dominant parameter in the calculation of the safety factor. However, calculation of the safety factors in the zone where the real failure occurred (indicated by a frame in Figure 18), does not exhibit a critical safety factor (less than 1). Contrary to the infinite slope stability method, the depth of the potential failure surfaces is not necessarily the critical depth defined at the beginning of the study. Despite the fixed depth of $50 \mathrm{~m}$ of the vertical cross-section, most critical surfaces occur at a depth less than $40 \mathrm{~m}$ (Figure 19).

\subsubsection{Seed's scenario}

After the Nice slope failure, several scenarios were proposed in order to find the cause of the accident. One of those scenarios was developed by Seed (according to Habib 1994). He supposed that the disturbance originated far from the coast (around $15 \mathrm{~km}$ ) and resulted from the collapse of a hundred million cubic meters of sediments. This offshore landslide would have been the cause of the progressive wave that reached the coast almost simultaneously, inducing a lowering of about $2.5 \mathrm{~m}$ of the sea level. The embankment of the airport extension was no longer submerged, which created a sudden load increase on the soil. Seed supposed that the lowering of the water level was enough to initiate the embankment failure.

Our model was applied to Seed's scenario in order to study the effect of the lowering of the $2.5 \mathrm{~m}$ of the sea level on the stability of the Nice slope. The sea level was considered 
at $-2.5 \mathrm{~m}$. For the sediment above $-2.5 \mathrm{~m}$, no buoyancy effect was considered in the safety factor calculation. As in the first scenario, the calculation was carried out under gravitational loading and for undrained condition along 2209 cross-sections. All the calculation steps were performed and the safety factor was determined at each node. The safety factor map of the Nice slope is presented in Figure 20. One can observe a decrease of the safety factor in the area surrounding the new Nice airport with respect to the classical gravitational loading calculation. However, the safety factors remained greater than one in the area indicated by a frame in Figure 20 (Figure 21-b). As in the case of the infinite slope stability, the failure condition was reached $(\mathrm{FOS}<1)$ in a local section of the under-consolidated sediment (Figure 20 and Figure 21-a).

\subsubsection{Pseudo-3D reconstruction of the failure surfaces.}

Although the limit equilibrium analyses described in the above paragraphs are applied to vertical cross-sections, slope instability is of course 3-D bowl shaped. In order to carry out an approximate three-dimensional reconstruction of the failure surface, a single safety factor and the corresponding depth of failure need to be assigned to each grid point of the sea floor. In each vertical cross-section, the minimal safety factor $(F O S)$ along each vertical grid line and the corresponding critical depth $\left(z_{c r i}\right)$ are affected to the upper node. From the definition of the vertical cross-sections, each grid point of the sea floor may belong to several cross-sections. Thus, depending on the considered cross-section, several safety factors may concern the same node. Only the minimal safety factor $\left(\mathrm{FOS}_{\mathrm{i}-\mathrm{j}}=\min \left[\mathrm{FOS}_{\mathrm{i}-\mathrm{j}}(\mathrm{A}-\mathrm{A}), \mathrm{FOS}_{\mathrm{i}-\mathrm{j}}(\mathrm{B}-\mathrm{B}), \ldots\right]\right)$ is considered and affected to each grid point with its associated critical depth (Figure 22). Over the whole area, the grid points corresponding to a given value of the safety factor exhibit several critical depths. An approximate reconstruction of the three-dimensional potential failure 
surface is possible by plotting the equal values of this critical depth $\left(\mathrm{z}_{\text {cri }}\right)$. In Figure 22, the 3-D failure surfaces corresponding to a safety factor less than 1 were interpolated from the critical depths $\left(z_{c r i}\right)$ of several cross-sections, showing bowl shaped failure surfaces.

This indirect reconstruction of the three-dimensional failure surface as well as the 3D safety factors is conservative. Indeed, Duncan (1996) by comparing the methods and results of several authors concludes that the factor of safety calculated using 3D analyses is always greater than or equal to the factor of safety calculated using 2D analyses.

Once the shape and the volume of the sediment above the potential failure surfaces are determined, a post failure study in relation with the dynamic of sediment motion can be performed. While the slump of cohesive sediment of low sensitivity occurs by a rigid movement of the volume above the shearing surface without a significant disturbance, the slip of sensitive clay and sand can be compared to an avalanche and can be easily transformed into a turbiditiy current. The study of the sediment transport is beyond the scope of this paper. However, in this work it was fundamental to identify the right geometry of the failure surface in order to give an adequate initial geometry for the problem of sediment flow and to simulate correctly the sediment transport and the turbidity currents.

\section{CONCLUSION}

The main objective of this work was to develop a new methodology (with respect to the conventional infinite slope stability method), which permits the calculation of the approximate three-dimensional safety factor over a large submarine area with complex bathymetry and heterogeneous sediment. The variation of the geotechnical parameters 
in the 3 directions of space was taken into account. For a given pore pressure boundary condition, the effect of the water flow on the submarine slope stability can be considered.

Since results from literature have shown that the safety factor calculated over an arbitrary slip surface does not involve large errors (less than $5 \%$ ), no restriction on the postulated shape of the failure surface was considered. The safety factor was considered as a spatially varying quantity and the General Formulation (GLE - Fredlund and Krahn 1977), which fully satisfies equilibrium conditions, was used for evaluating the stability of the marine slope. A two-dimensional calculation was performed on a large number of vertical sections crossing the area and was extended to the three-dimensional zone. Determination of the shape and the volume of the potential failure surface was necessary to ensure that an appropriate initial condition for the problem of the post failure mechanism (sediment flows and turbidity currents) is defined.

The developed methodology was tested through the calculation of the Nice slope instability. Two cases of instability were studied:

1) under a static conditions ;

2) under a lowering of $2.5 \mathrm{~m}$ of the sea level (Seed's scenario).

For the static conditions, the safety factors calculated in the zone where the failure occurred in 1979 (indicated by a frame in Figure 18) did not show an instable zone (safety factors greater than 1). The scenario of a sea level lowering due to the collapse of a hundred million cubic meters of sediments far from the coast (Sceed's scenario) showed a decrease of the safety factor (with respect to the static gravitational loading calculation - Figure 20) in the area surrounding Nice new airport. However, the safety 
factors were remained greater than 1 in the area where the failure occurred in 1979 (Figure 20). These calculation results are related to:

1) the geotechnical characteristics used in the calculation are those of the sediment which have resisted to the slope failure of 1979 ;

2) The bathymetry of the Nice slope is a compilation of pre-failure data for depths ranging from 0 to $150 \mathrm{~m}$ and post-failure data for the deeper part.

In the lack of relevant pre-failure bathymetry data and geotechnical characteristics, it is impossible to identify the origin of the Nice slope failure of 1979 . However, a future site survey in a restricted area of the Nice slope will be carried out by the IFREMER in order to identify an accurate:

1) morphology of the seabed using the High Resolution multi-beam echo-sounder ;

2) geometry of the slope using a $V H R$ (Very High Resolution) 3-D seismic technique ;

3) geotechnical parameters using the $C P T$ (Cone Penetration Test).

Acquisition of such data will permit an accurate quantitative calculation of the safety factor of the Nice slope and a prevision of a possible future geo-hazards accident in the area. 


\section{REFERENCES}

Almagor, G. and G. Wisman. 1977. Analysis of submarine slumping in the continental slope off the southern coast of Israel. Marine Geotechnology 2: 349-388.

Auffret, G. A., J. M., Auzende, M., Gennessaux, S., Monti, L., Pastouret, G., Pautot and J. R. Vanney. 1982. Recent mass wasting processes on the provencal margin (Western Mediterranean). Proc.of a NATO Workshop on marine slides and other mass movements. Portugal: 15-21.

Berné, S., M., Canals, B., Alonso, B., Loubrieu and P. Cochonat. 1998. Recent slope failures and mass-movements in the NW Mediterranean sea. Proc. 3rd Europ. Marine Science and Technology Conference. Lisbon: 111-126.

Bishop, A. W.. 1955. The use of the slip circle in the stability analysis of slopes. Géotechnique 5: 7-17.

Booth, J.S. and D.W. O'Leary. 1991. A statistical overview of mass movement characteristics on the North American Atlantic outer continental margin. Marine Geotechnology 10: 1-18.

Bourillet, J.-F.. 1991. Géomorphologie à partir d'un modèle numérique de terrain (Baie des Anges, Nice). Proc. 3ème congrès Français de Sédimentologie. Brest 15: 51.

Bourillet, J.-F., C., Edy, and A., Normand. 1992. Nouvel ensemble pour la reconnaissance du plateau continental: Sondeur multifaisceaux EM1000 et logiciel Trismus. Un exemple : la Baie des Anges (France). CIESM, Rapp. Comm. int. Mer Médit.. Monaco 33: 112.

Bugge, T., S., Befring, R.H., Belderson, T. Eidvin, E., Jansen, N.H., Kenyon, and H.P., Sejrup. 1987. A giant three-stage submarine slide off Norway. Geo-Marine Letters 7: 191-198. 
Chen, W. F.. 1975. Limit Analysis and Soil Plasticity. Elsevier, Amsterdam.

Chen W. F. and M. W., Giger. 1971. Limit analysis of stability of slopes. Journal of Soil Mechanics and Foundation Engineering Division, ASCE 97(1): 19-26.

Cochonat, P., J.-F., Bourillet, B., Savoye. 1993. Geotechnical characteristics and instability of submarine slope sediments, the Nice slope (N-W Mediterranean sea). Marine Georesources and Geotechnology 11: 131-151.

Coleman, J. M. and L. E., Garrison. 1977. Geological aspects of marine slope stability, Northwestern gulf of Mexico. Marine Geotechnology 2: 9-44.

Duncan, J. M.. 1996. State of the art: limit equilibrium and finite-element analyses of slopes. Journal of Geotechnical Engineering Division 122(7): 577-596.

Embley, R. W.. 1980. Anatomy of some Atlantic margin sediment slides and some comments on ages and mechanisms. In: Saxov, S., Nieuwenhuis, J. K. (Editors), Marine Slides and other Mass Movements. Nato Scientific Affairs Division: 189-213.

Embley, R. W. and R., Jacobi. 1977. Submarine sediment slides and slumps on Atlantic continental margins. Marine Geotechnology 2: 205-228

Espinoza, R. D., P. C., Repetto and B., Muhunthan. 1992. General framework for stability analysis of slopes. Géotechnique 42(4): 603-615.

Fredlund, D. G. and J., Krahn. 1977. Comparison of slope stability methods of analysis. Canadian Geotechnical Journal 14: 429-439.

Habib, P.. 1994. Aspects géotechniques de l'accident du nouveau port de Nice. Revue Française de Géotechnique 65 : 3-15.

Gennesseaux, M., A., Mauffret and G., Pautot. 1980. Les glissements sousmarins de la pente continentale niçoise et la rupture de cables en mer Ligure 
(Méditerranée occidentale). Comptes Rendus de l'Académie des Sciencesde Paris, Série II 290: 959-963.

Hampton, M. A. and A. H., Bouma. 1977. Slope instability near the shelf break, western gulf of Alaska. Marine Geotechnology 2: 309-331.

Karal, K.. 1977. Energy method for soil stability analyses. Journal of Geotechnical Engineering Division 5: 431-445.

Malinverno, A., W.B.F., Ryan, G., Auffret and G., Pautot.1988. Sonar images of the path of recent failure events on the continental margin off Nice, France, Geological Society of America Special Paper 229:59-76.

McGregor, B. A..1977. Geophysical assessment of submarine slide Northeast of Wilmington Canyon. Marine Geotechnology 2:229-261.

Michalowski, R. L.. 1995. Slope stability analysis: a kinematical approach. Géotechnique 45(2): 283-293.

Morgenstern, N. R.. 1967. Submarine slumping and the initiation of turbidity currents. In: Richards, A. F. (Editor), Marine Géotechnique. University of Illinois Press: 189-220.

Morgenstern, N. R. and V. E., Price. 1965. The analysis of the stability of generalised slip surfaces. Géotechnique 15: 79-93.

Mulder, T. and P., Cochonat. 1996. Classification of offshore mass movements. Journal of Sedimentary Research 66: 43-57.

Mulder, T., J.-P., Tisot, P., Cochonat and J.-F., Bourillet. 1994. Regional assessment of mass failure events in the Baie des Anges Mediterranean sea. Marine Geology 122: 29-45. 
Nash, D.. 1987. A comparative review of limit equilibrium methods of stability analysis. In: Anderson, M. G., Richards, K. S. (Editors), Slope Stability. John Wiley \& Sons: 11-75.

Orren, R. and I., Hamilton. 1998. Frontier geohazard site investigationsexperience from the Caspian sea. Proc. Int. Conf. Offshore Site Investigation and Foundation Behaviour. Society for Underwater Technology, London: 467-490.

Pautot, G.. 1981. Cadre morphologique de la Baie des Anges (Nice-Côte d'Azur): modèle d'instabilité de pente continentales; Ocean. Acta 4(2): 203-211.

Piper, D. J. W. and B., Savoye. 1993. Processes of late quaternary turbidity current flow and deposition on the Var deep-sea fan, north-west Mediterranean Sea. Sedimentology 40: 557-582.

Savoye, B., P., Cochonat, G., Ollier, G.A., Auffret and J.-F., Bourillet. 1989. The submarine Var Canyon (French Riviera): detailed study of the activity of a modern canyon. $10^{\text {th }}$ Regional Meet. Sedimentology.

Savoye, B., D.J.W., Piper and L., Droz. 1993. Plio-Pleistocene evolution of the Var deep-sea fan off the French Riviera. Mar. Petrol. Geol. 10: 550-571.

Skempton, A. W.. 1954. Discussion of the structure of inorganic soil. J. Soil Mechanics and Foundation Division, ASCE 80(478): 263-264.

Spencer, E.. 1967. A method of analysis of the stability of embankments assuming parallel interslice forces. Géotechnique 17: 11-26.

Taylor, D. W.. 1948. Fundamentals of Soil Mechanics. Wiley, New York. Zienkiewicz, O.C, and I.C., Cormeau. 1974. Viscoplasticity, plasticity and creep in elastic solids. A Unified Numerical Solution Approach. Int. J. Num. Meth. Eng. 8: $821-845$ 


\section{LIST OF FIGURES}

Figure 1. Bathymetric chart of the Nice slope (IFREMER data).

Figure 2. Geographical distribution of the four consolidation states of the sediment (A,

B, C and D) over the Nice slope area (after Cochonat et al. 1993 (Fig. 12)).

Figure 3. Slope angle map.

Figure 4. Geometrical meaning of $\alpha$ and $\beta$.

Figure 5. Cross-sections cut into the Nice slope.

Figure 6. Grid generation on a vertical cross-section.

Figure 7. a) Mohr-Coulomb criterion for $c^{\prime}-\varphi^{\prime}$ material and b) log-spiral rigid rotational mechanism.

Figure 8. a) definition of the parameters considered in the calculation b) comparison between limit equilibrium method and limit analysis method.

Figure 9. Automatic generation of concave failure surfaces.

Figure 10. Potential sliding surface and forces acting on an infinitesimal slice.

Figure 11 . Safety factor charts for slope angle of $45^{\circ}$ submitted to a) gravity loading and b) weak clay layer.

Figure 12. Comparison between limit equilibrium method (slices, circle, logspiral and arbitrary failure surface) and limit analysis method. 
Figure 13. (a) Mesh, (b) yielding and (c) displacement field for a slope angle of $45^{\circ}$ and for a uniform soil.

Figure 14. (a) yielding and (b) displacement field for a slope angle of $45^{\circ}$ with a weak clay layer.

Figure 15. FOS obtained with the finite element method for uniform and heterogeneous soil.

Figure 16. Infinite slope stability.

Figure 17. Safety factor map from an infinite slope analysis.

Figure 18. Safety factor map from a generalised limit equilibrium method.

Figure 19. Equal values of the factor of safety along a) the A-A cross-section and b) the B-B cross-section.

Figure 20. Safety factor map from a generalised limit equilibrium method using Seed's scenario.

Figure 21. Equal values of the factor of safety along a) the A-A cross-section and b) the B-B cross-section using Seed's scenario.

Figure 22. Approximate three-dimensional reconstruction of the failure surface. 


\begin{tabular}{|l|l|l|}
\hline & 1 & Safety factor $F$ \\
Unknowns & $\mathrm{n}$ & Normal total forces $P_{i}$ on base of slice \\
& $\mathrm{n}-1$ & Shear forces $T_{i}$ \\
& $\mathrm{n}-1$ & Interslice vertical forces $X$ \\
& $\mathrm{n}-1$ & Heights of the point of application $h_{i}$ of the internal horizontal forces \\
\hline Equations & $3 \mathrm{n}$ & Static equilibrium provides 3 equations fore each slice \\
& $\mathrm{n}$ & Mohr-Coulomb law gives a relation between normal $P_{i}$ and shear \\
unknown & $\mathrm{n}-2$ & forces $T_{i}$ at each base \\
\hline Hypothesis & $\mathrm{n}$ & Since the slices are considered as thin, one can consider that the normal \\
& force $P_{i}$ acts on the base centre \\
\hline Total & & \\
\hline
\end{tabular}

Table 1. Forces involved in equilibrium methods. 


\begin{tabular}{|c|c|c|c|c|c|c|}
\hline \multirow{3}{*}{$\begin{array}{c}\text { Slope } \\
\left(^{\circ}\right)\end{array}$} & \multirow{3}{*}{$\begin{array}{l}\varphi^{\prime} \\
\left(^{\circ}\right)\end{array}$} & \multicolumn{5}{|c|}{$\gamma \mathrm{H} / \mathrm{c}$} \\
\hline & & \multicolumn{3}{|c|}{ Limit Equilibrium } & \multirow{2}{*}{$\begin{array}{c}\text { Limit } \\
\text { Analysis } \\
\text { (Logspiral) }\end{array}$} & \multirow{2}{*}{\begin{tabular}{|c|} 
Limit \\
Equilibrium \\
(Arbitrary)
\end{tabular}} \\
\hline & & Slice & Circle & Logspiral & & \\
\hline 45 & 0 & 5.88 & 5.88 & 5.88 & 5.53 & 5.88 \\
\hline 30 & 0 & 6.41 & 6.41 & 6.41 & 5.53 & 6.2 \\
\hline 30 & 15 & 20.84 & 21.74 & - & 21.69 & 21.72 \\
\hline
\end{tabular}

Table 2. Safety Number Calculated by Different Methods. 


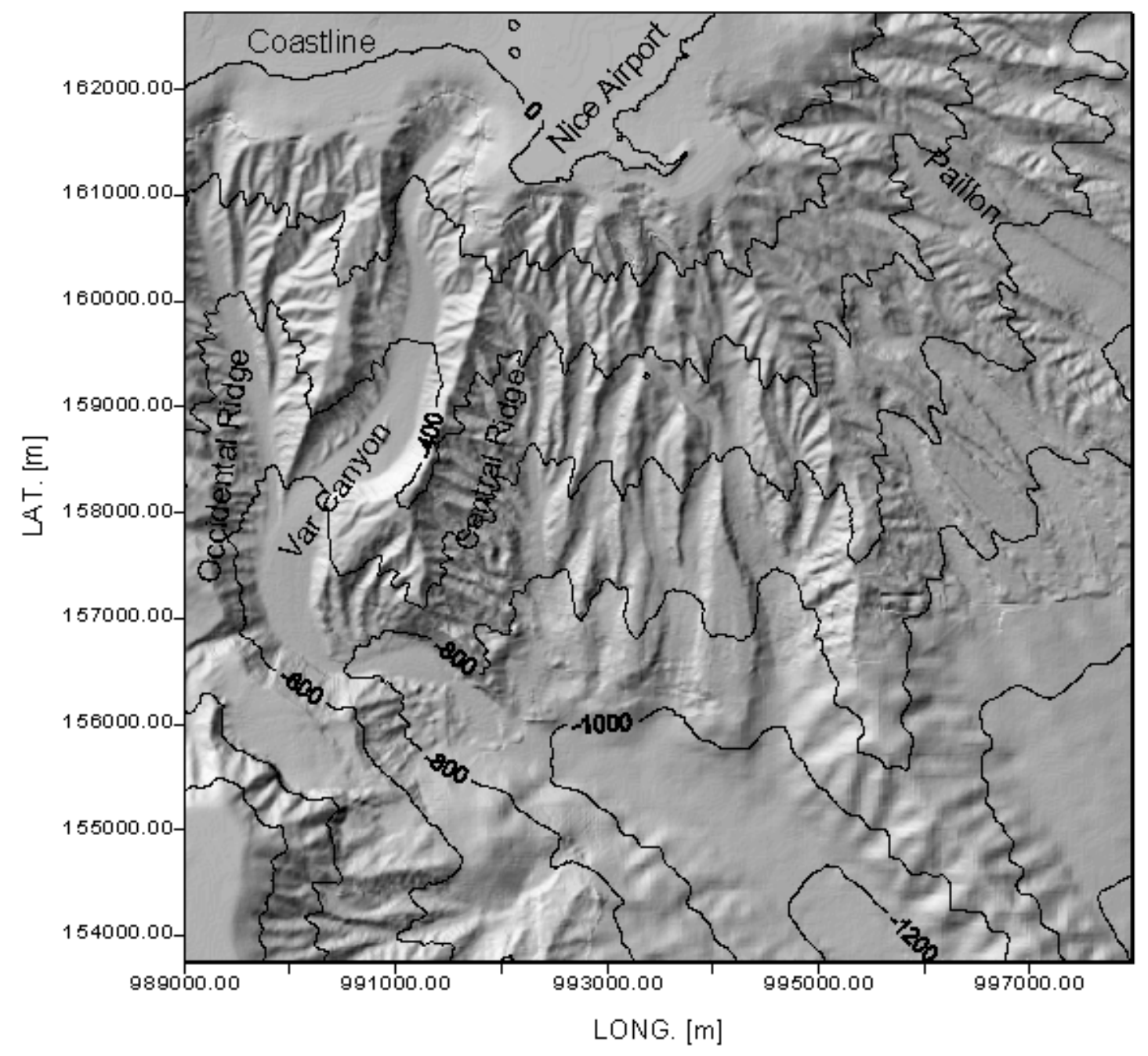

Figure 1. Bathymetric chart of the Nice slope (IFREMER data). 


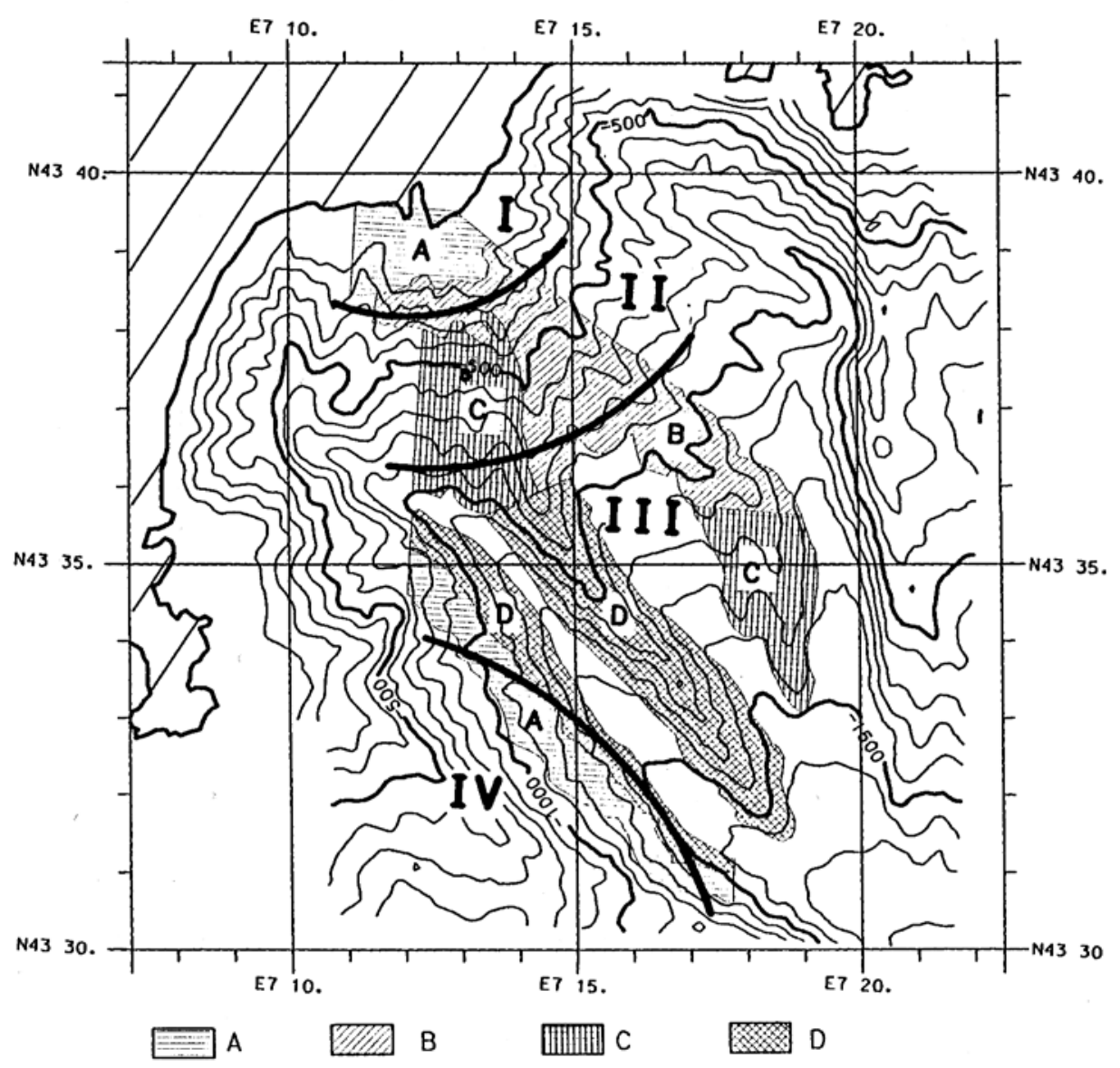

Figure 2. Geographical distribution of the four consolidation states of the sediment (A, B, C and D) over the Nice slope area (after Cochonat et al. 1993 (Fig. 12)). 


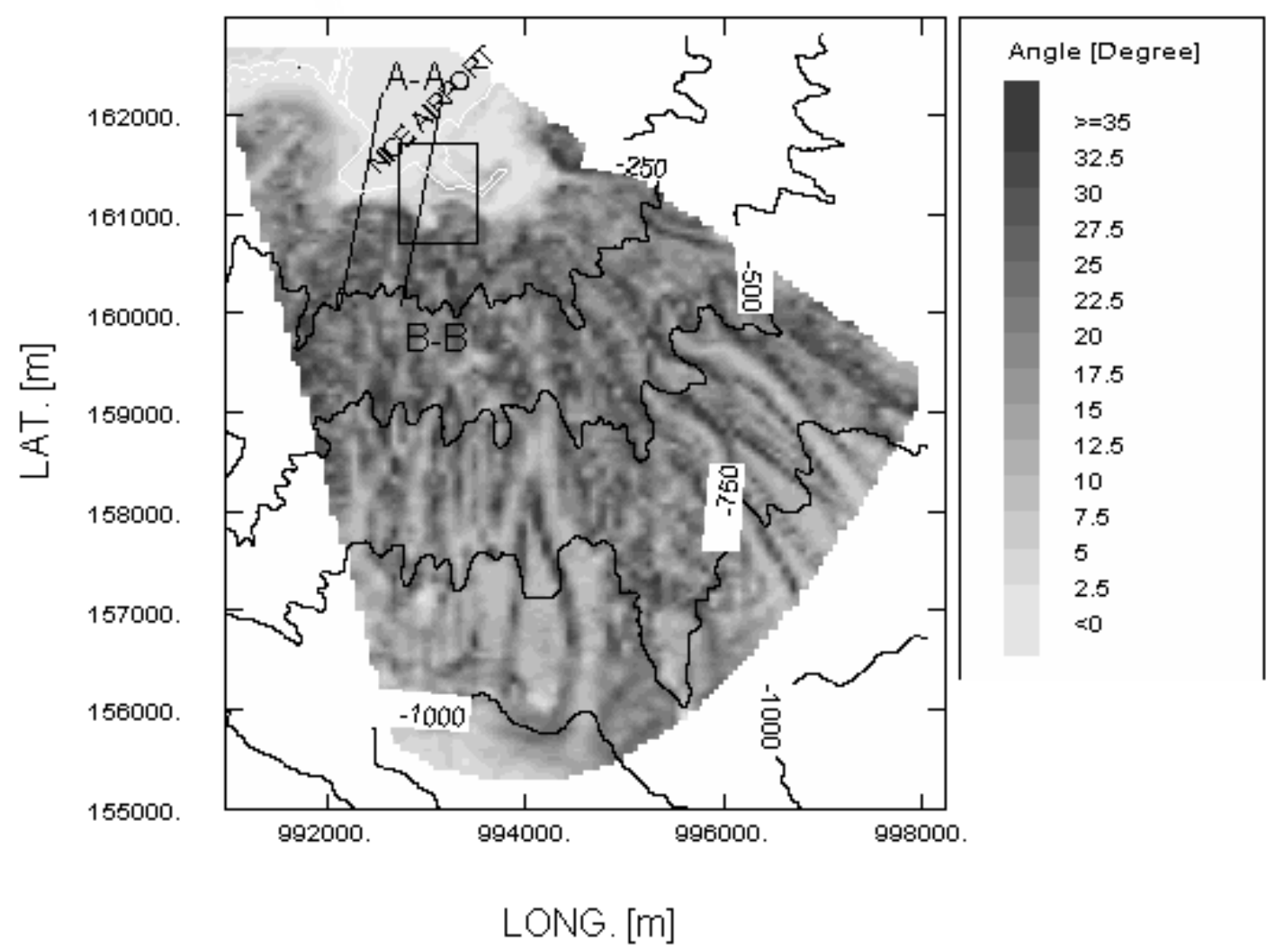

Figure 3. Slope angle map. 


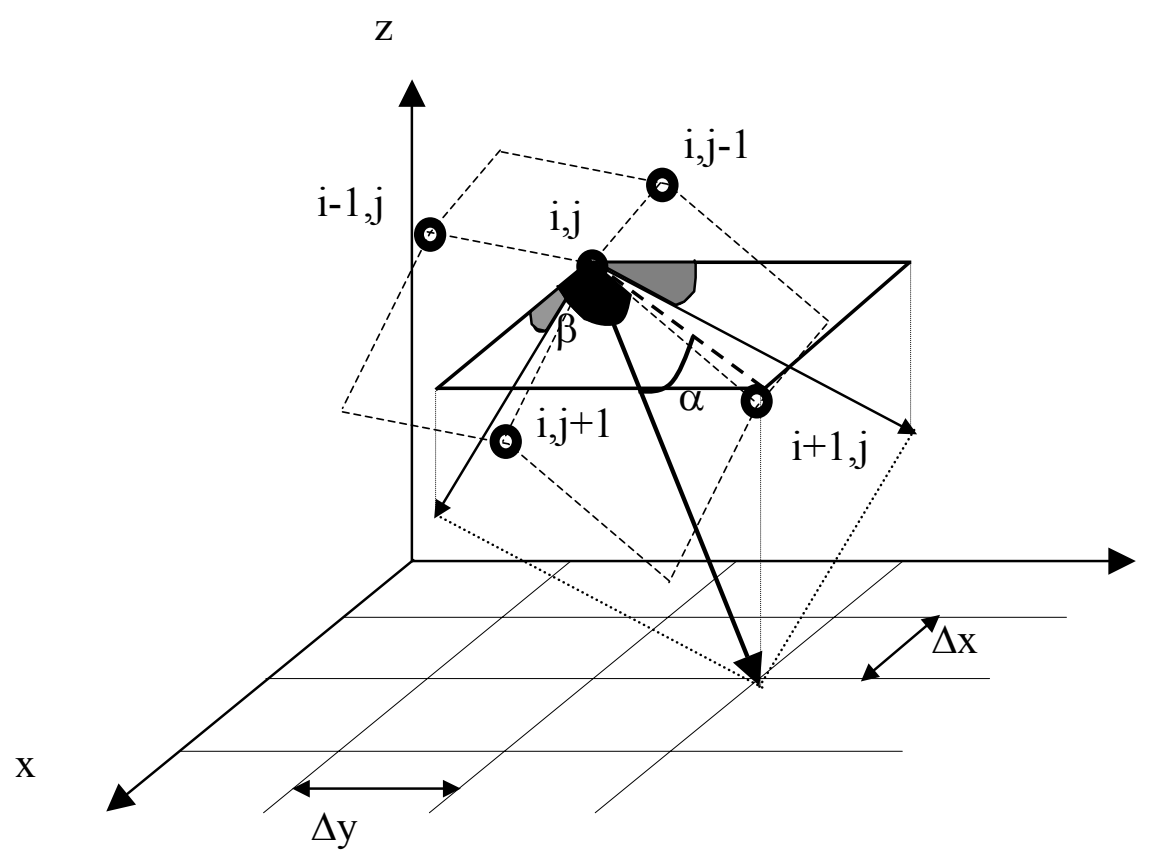

Figure 4. Geometrical meaning of $\alpha$ and $\beta$. 


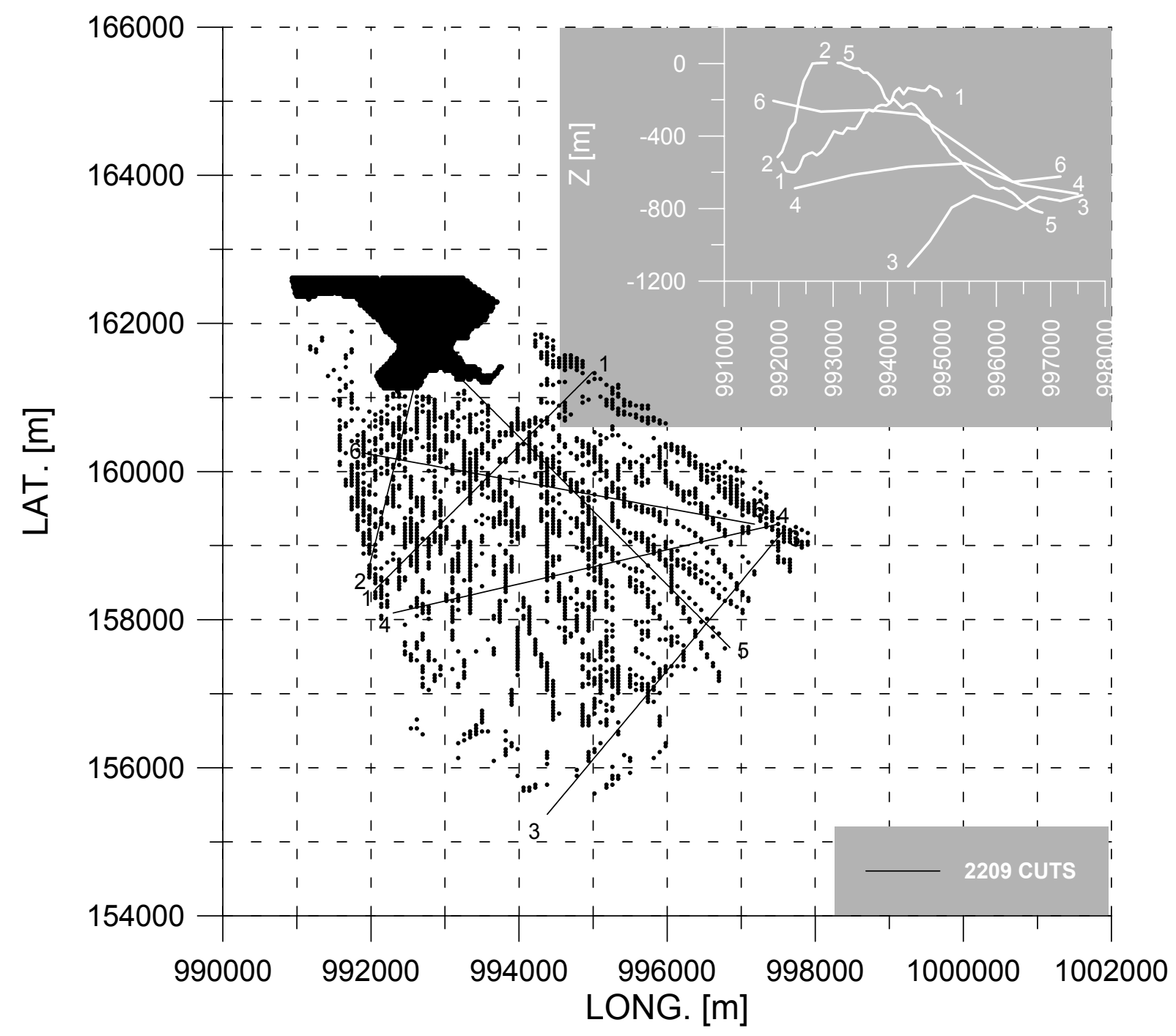

Figure 5. Cross-sections cut into the Nice slope. 


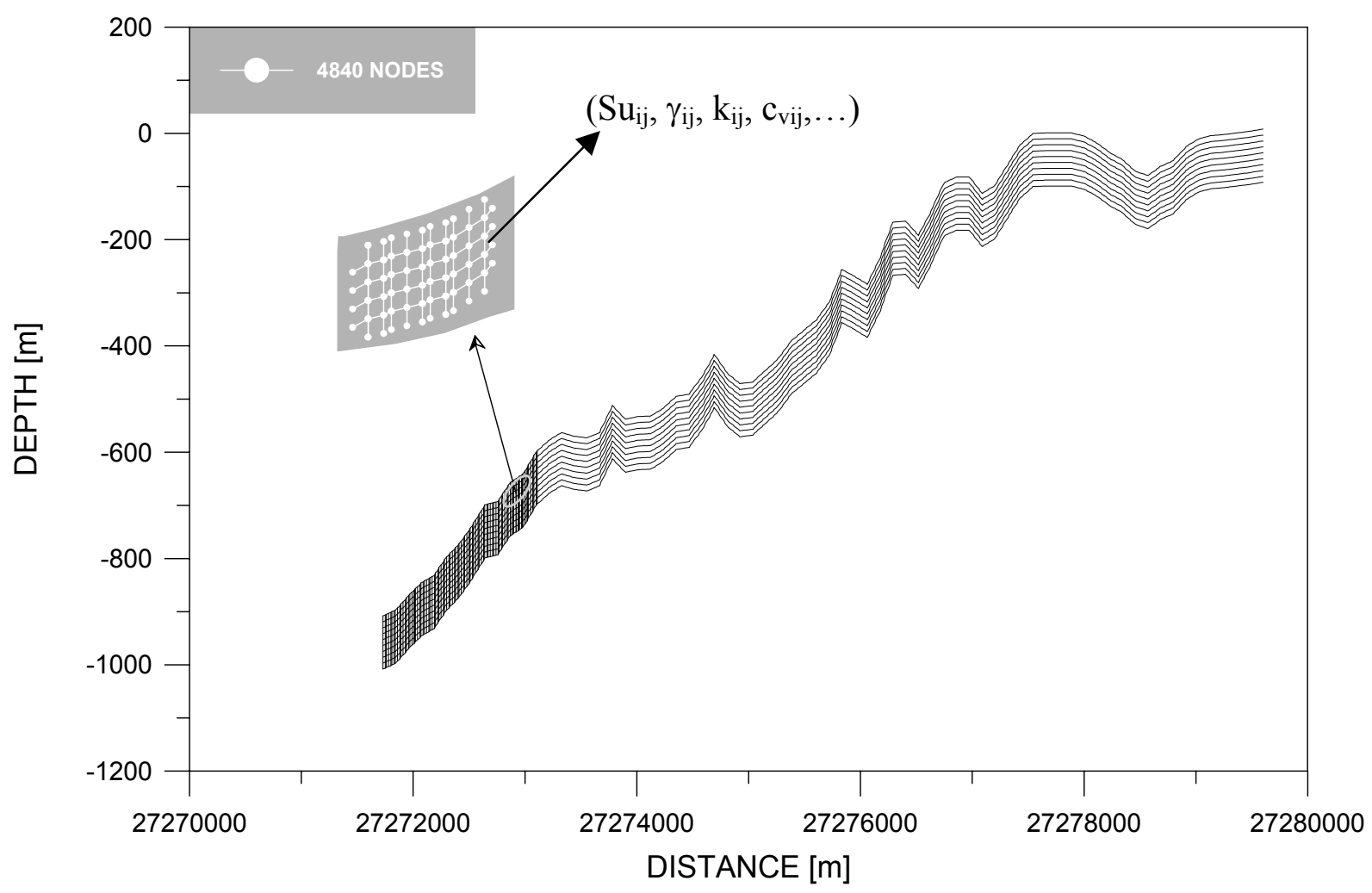

Figure 6. Grid generation on a vertical cross-section. 

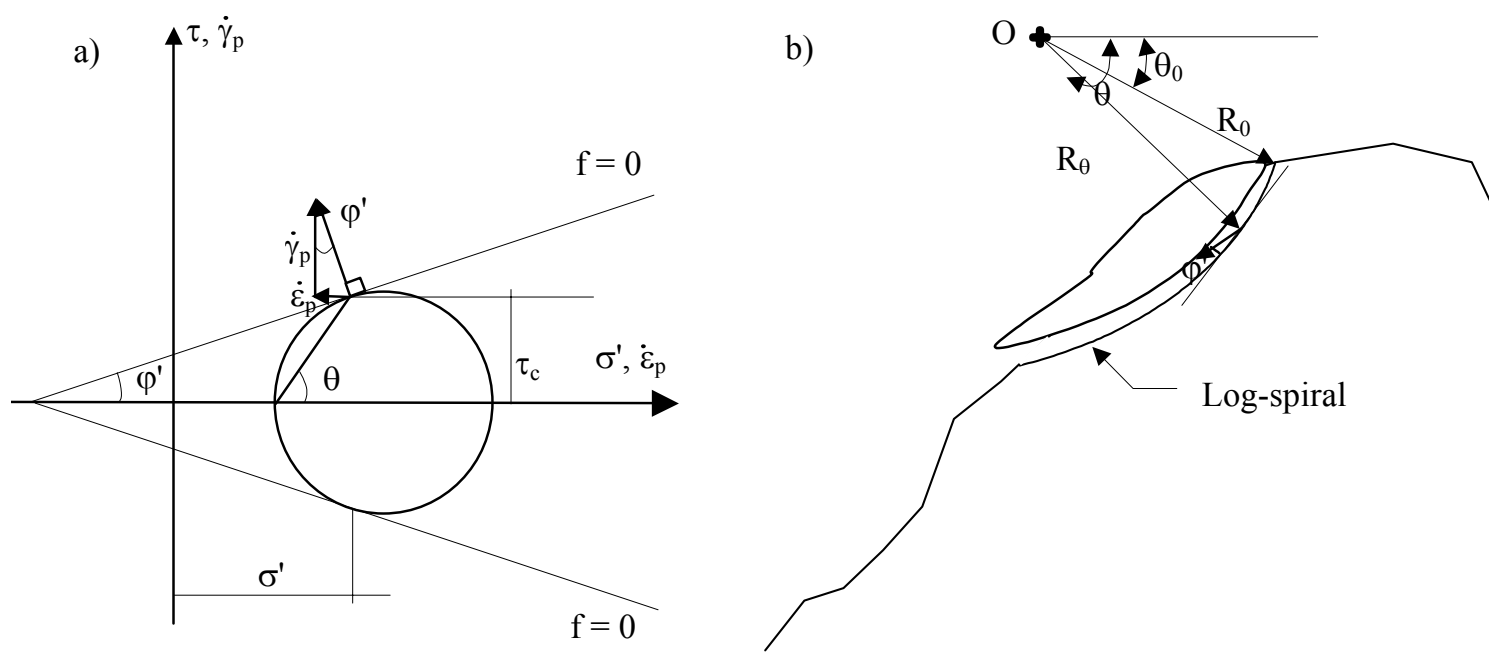

Figure 7. a) Mohr-Coulomb criterion for $c^{\prime}-\varphi^{\prime}$ material and b) log-spiral rigid rotational mechanism. 


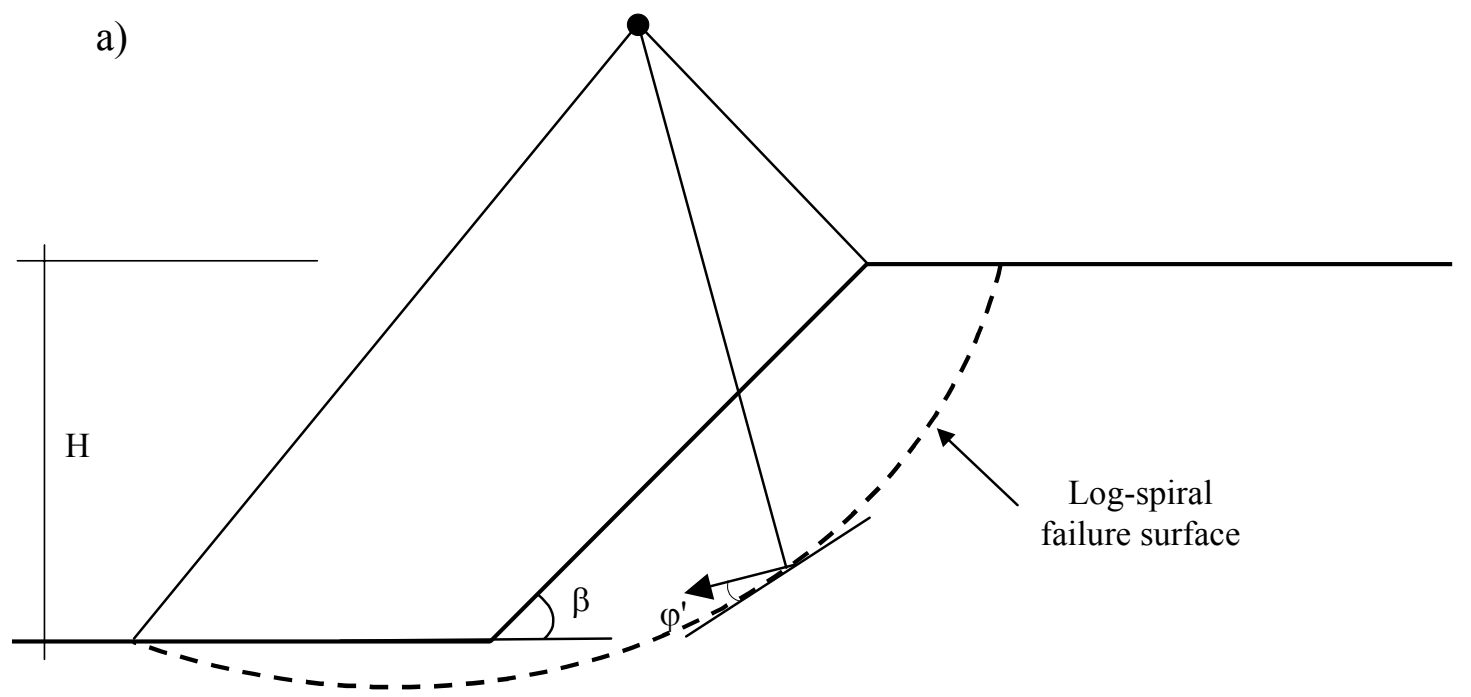

b)

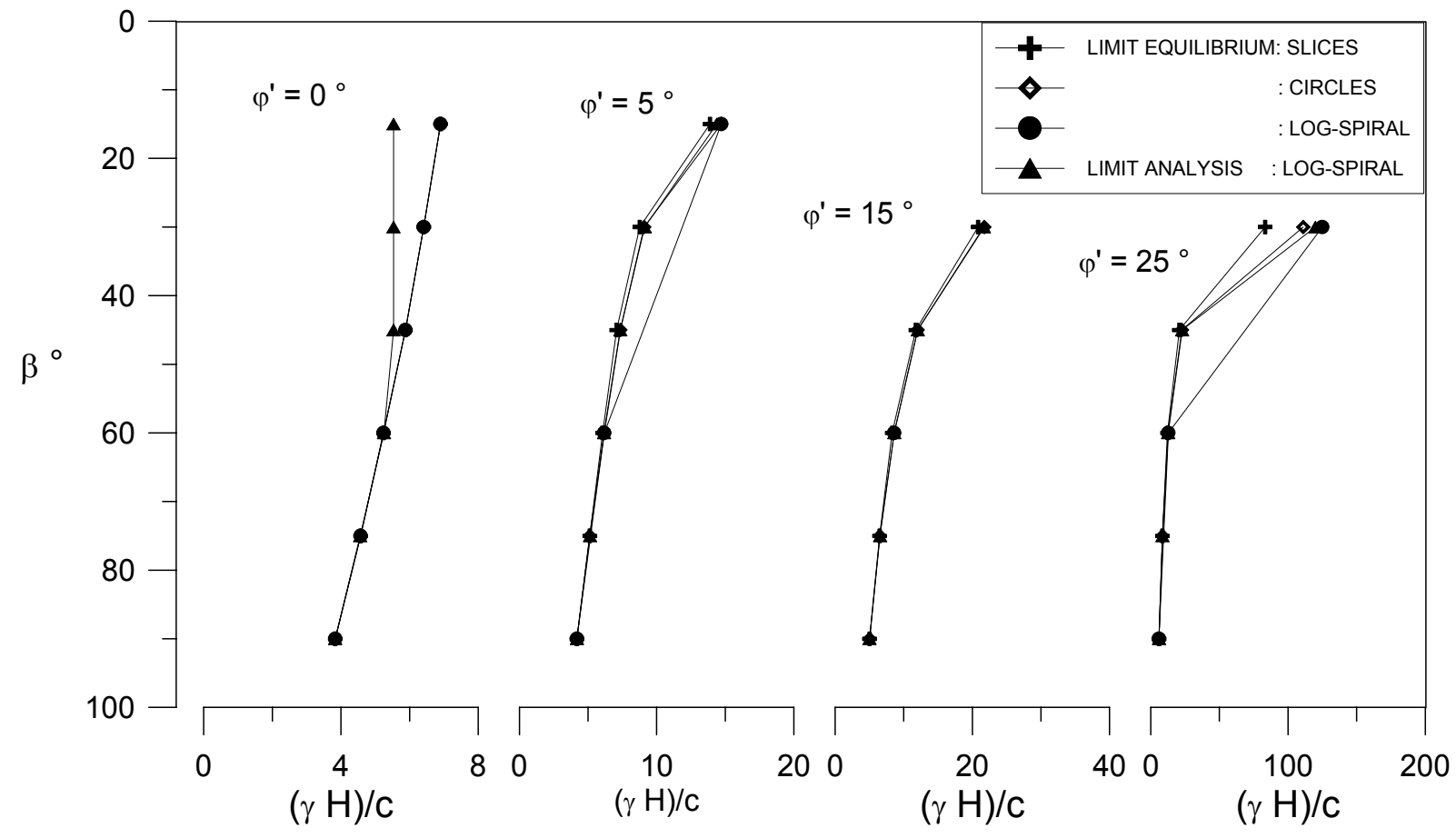

Figure 8. a) definition of the parameters considered in the calculation b) comparison between limit equilibrium method and limit analysis method. 


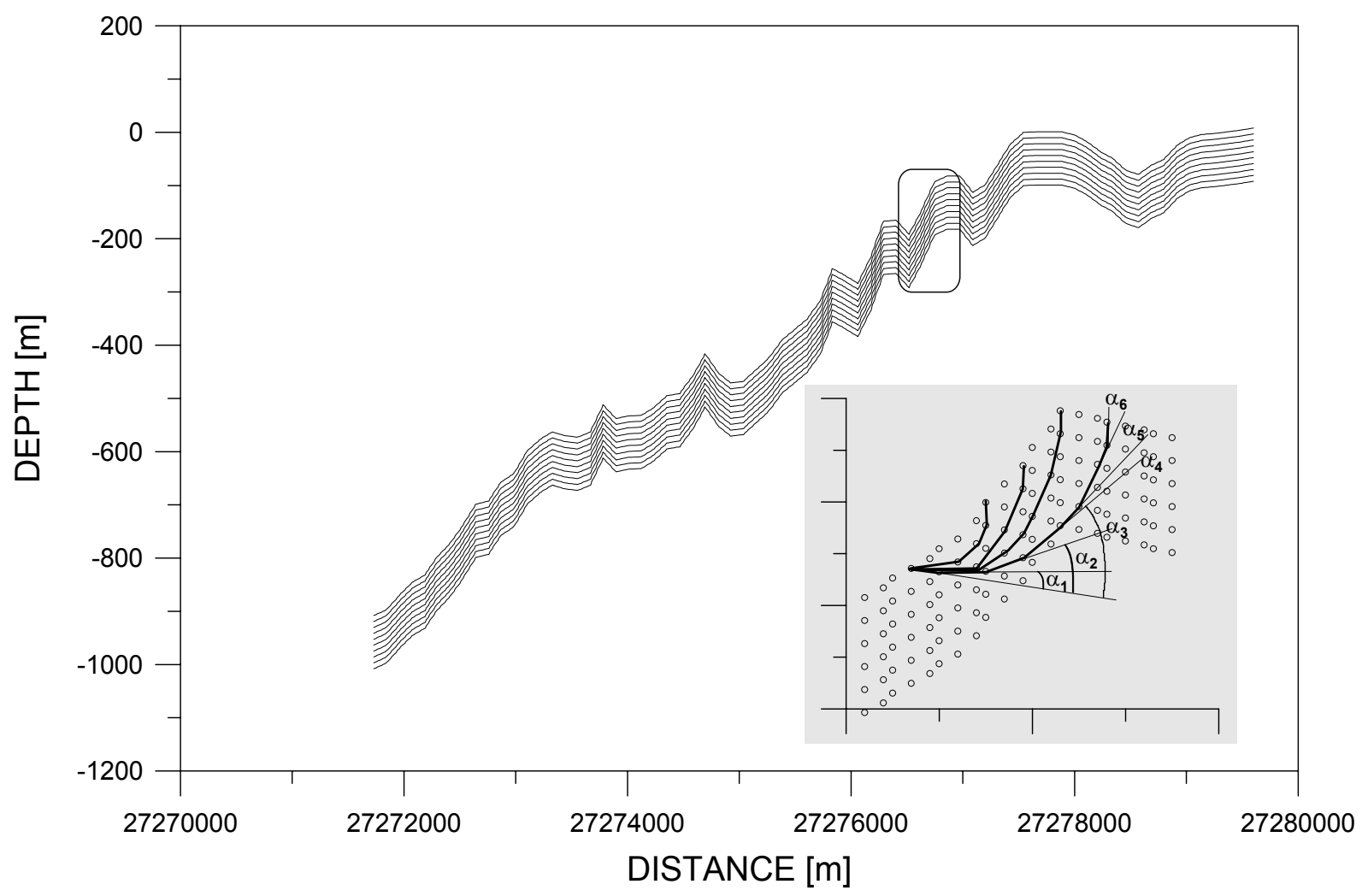

Figure 9. Automatic generation of concave failure surfaces. 


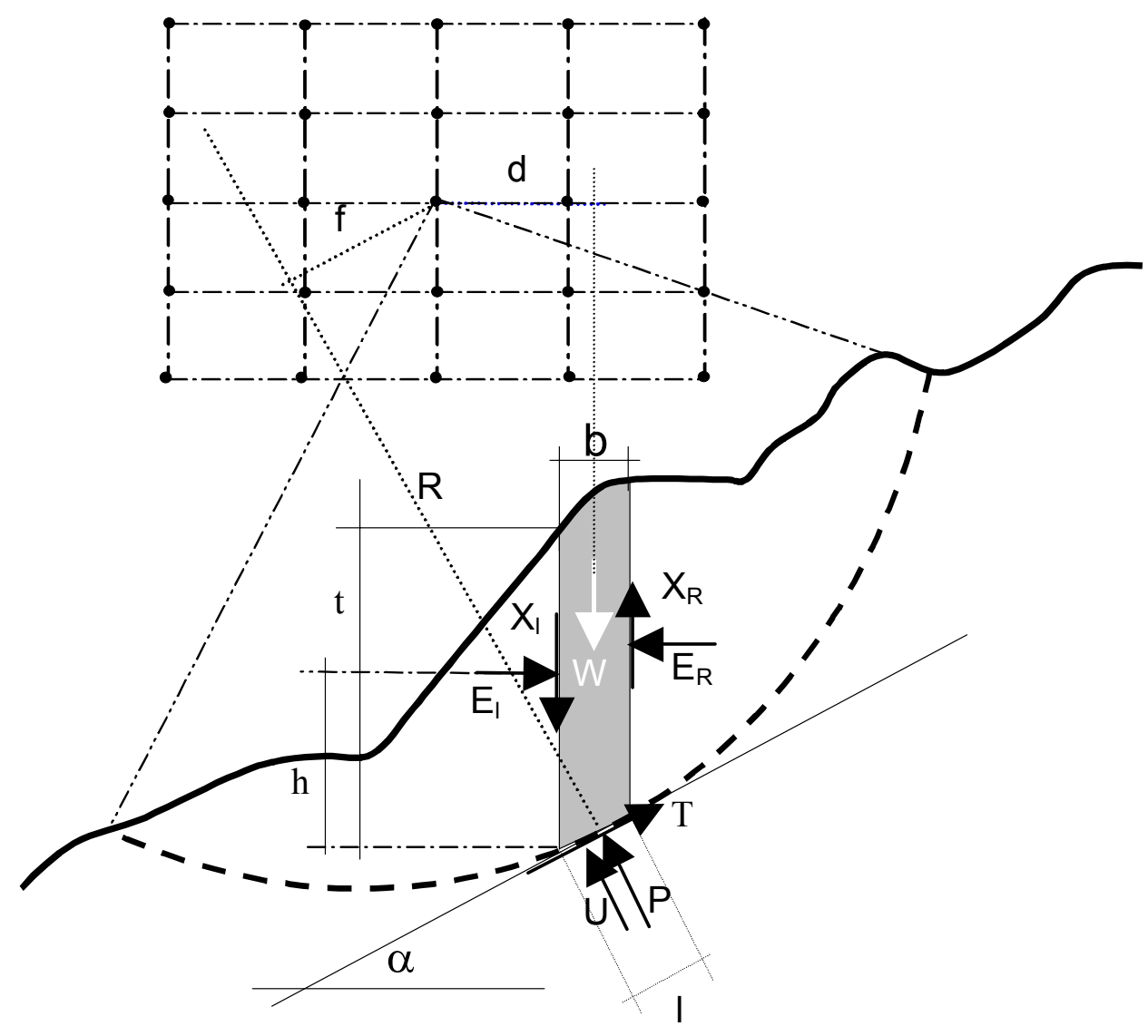

Figure 10. Potential sliding surface and forces acting on an infinitesimal slice. 

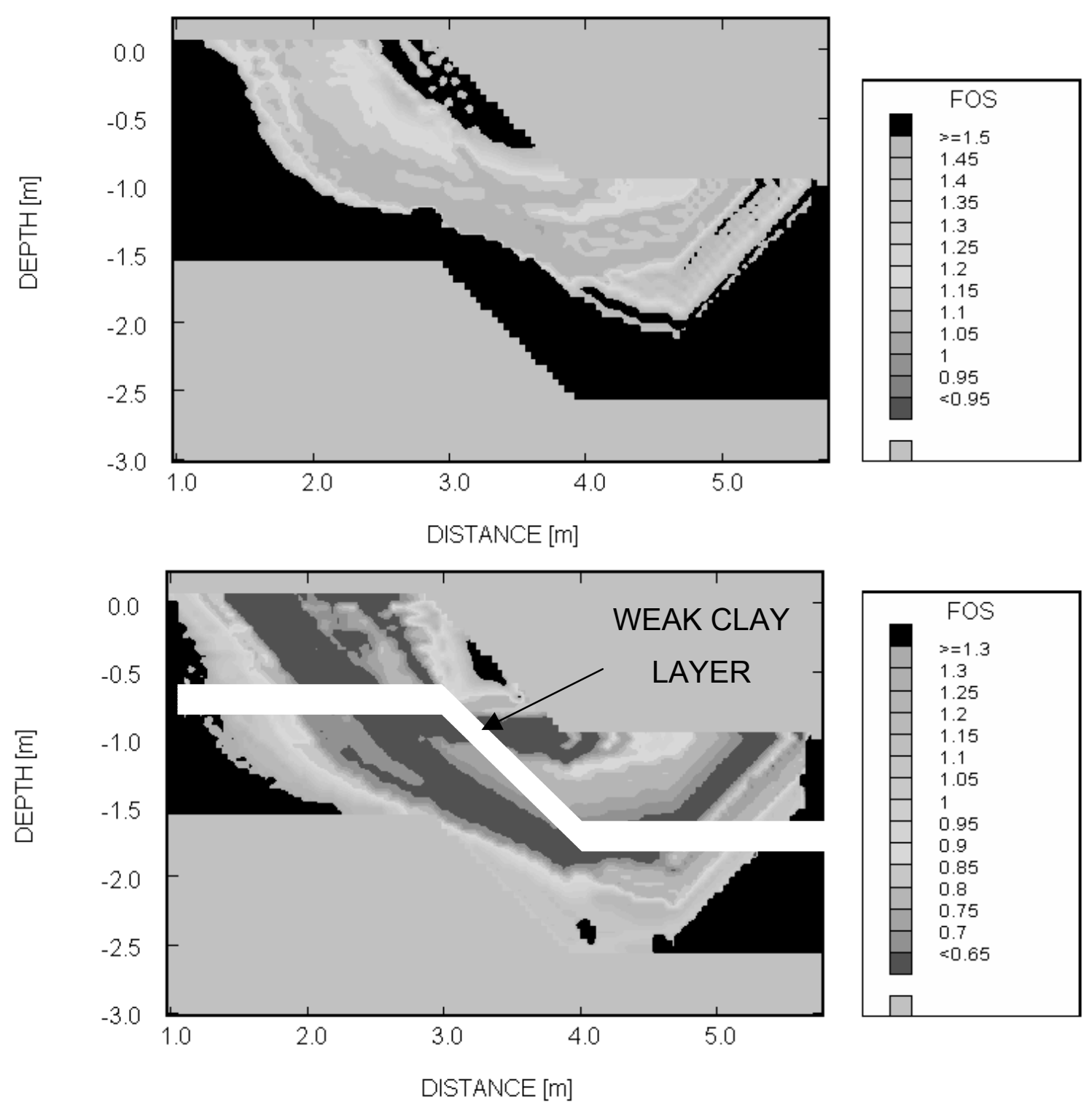

Figure 11. Safety factor charts for slope angle of $45^{\circ}$ submitted to a) gravity loading and b) weak clay layer. 


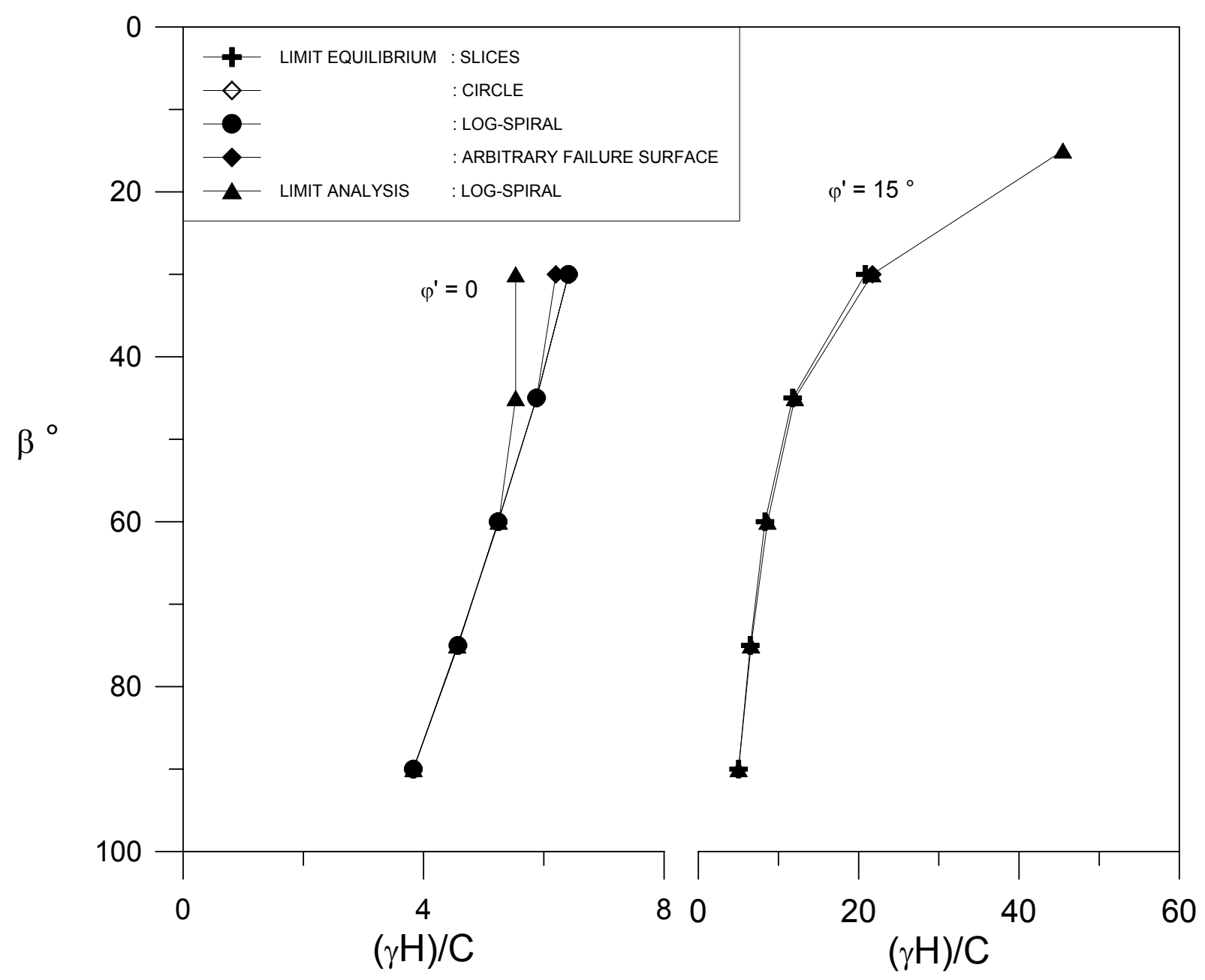

Figure 12. Comparison between limit equilibrium method (slices, circle, logspiral and arbitrary failure surface) and limit analysis method. 

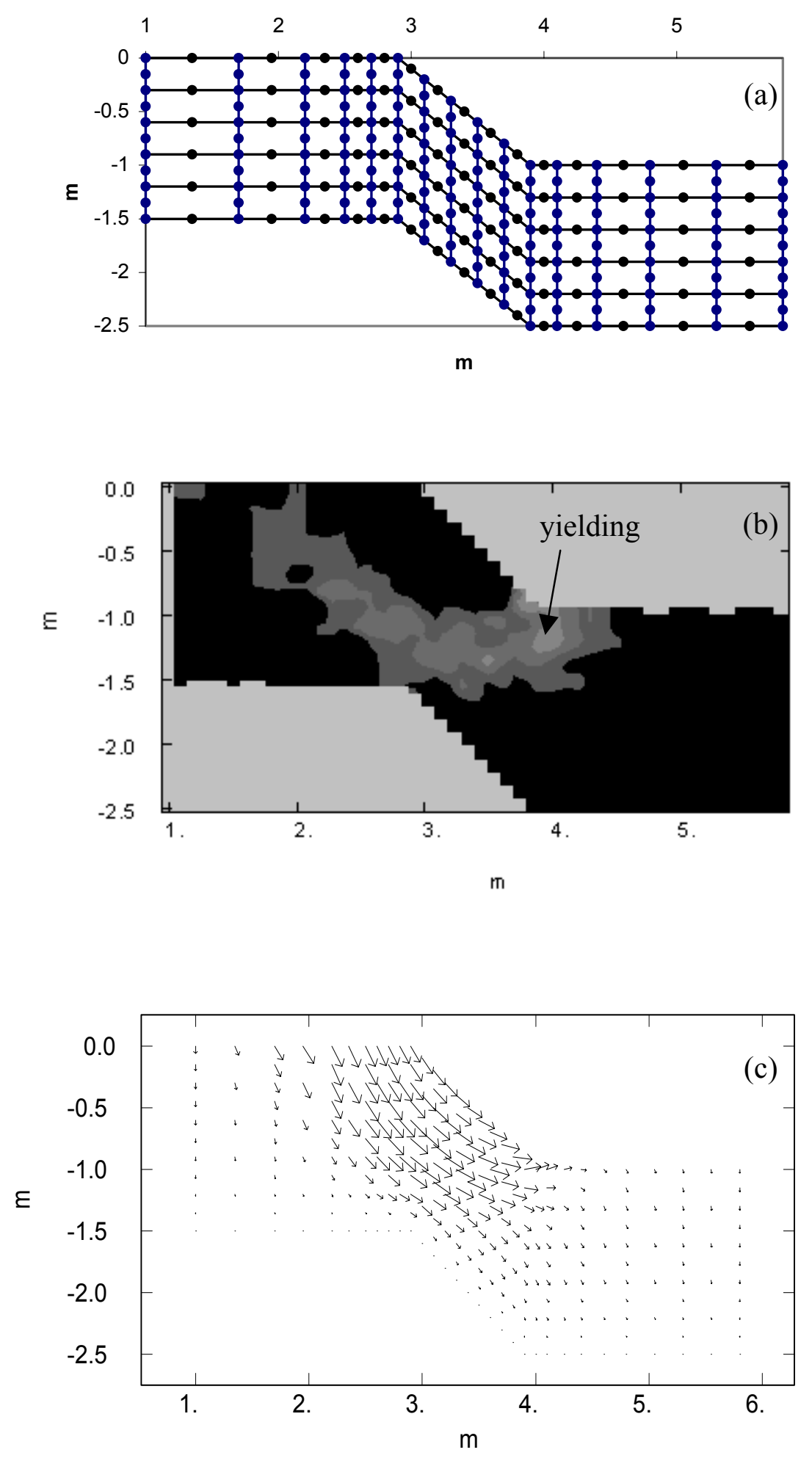

Figure 13. (a) Mesh, (b) yielding and (c) displacement field for a slope angle of $45^{\circ}$ and for a uniform soil. 

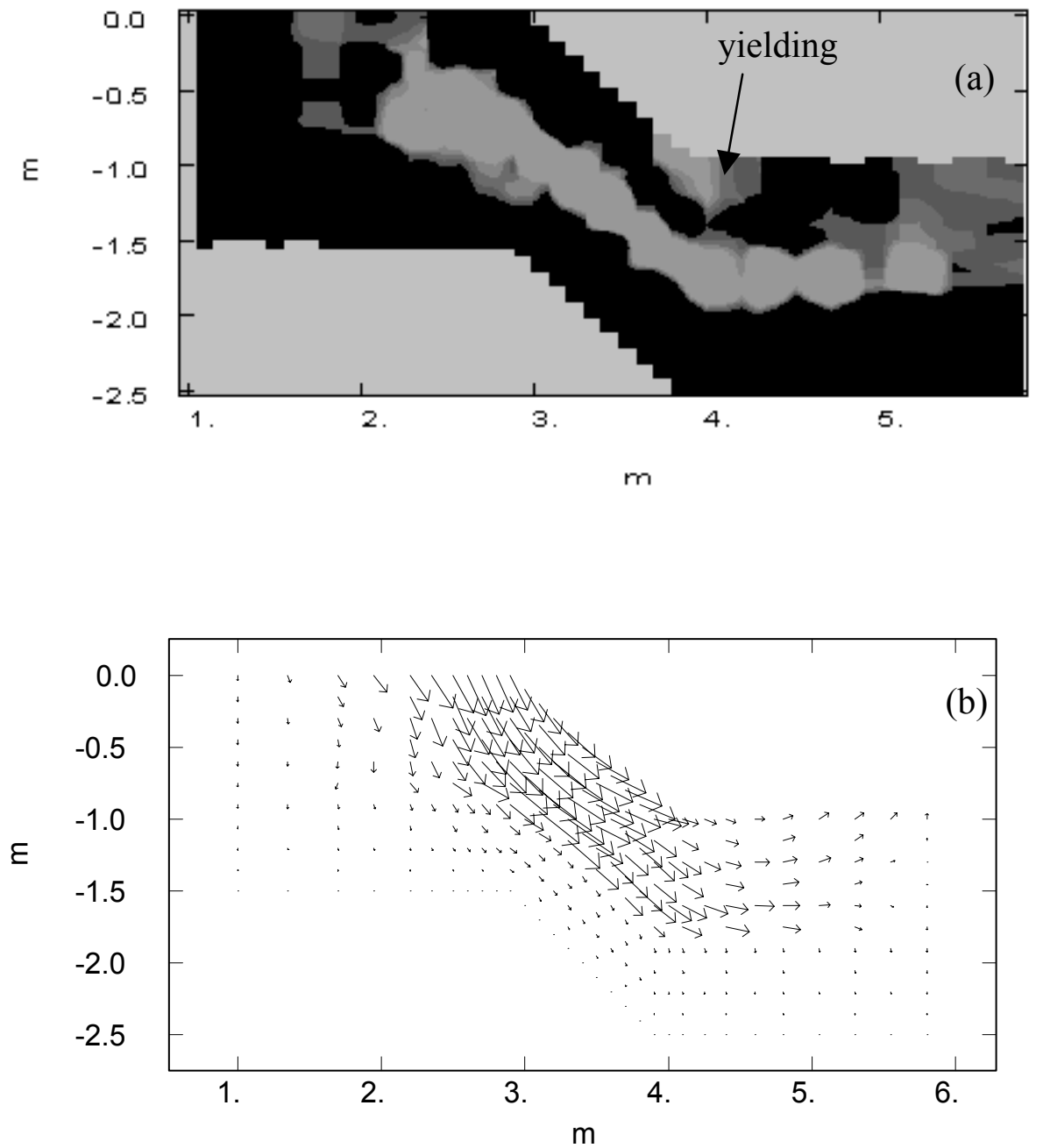

Figure 14. (a) yielding and (b) displacement field for a slope angle of $45^{\circ}$ with a weak clay layer. 


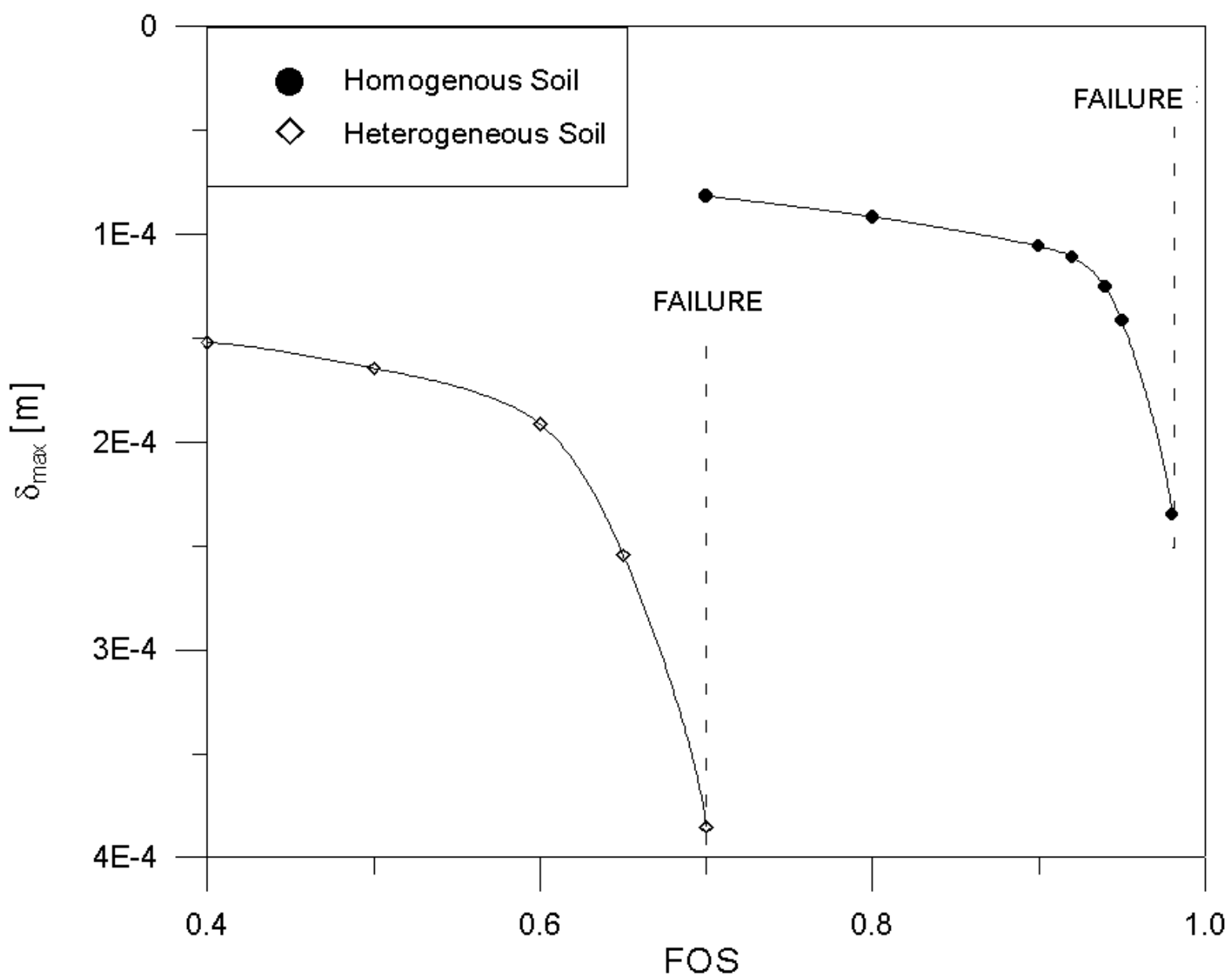

Figure 15. FOS obtained with the finite element method for uniform and heterogeneous soil. 


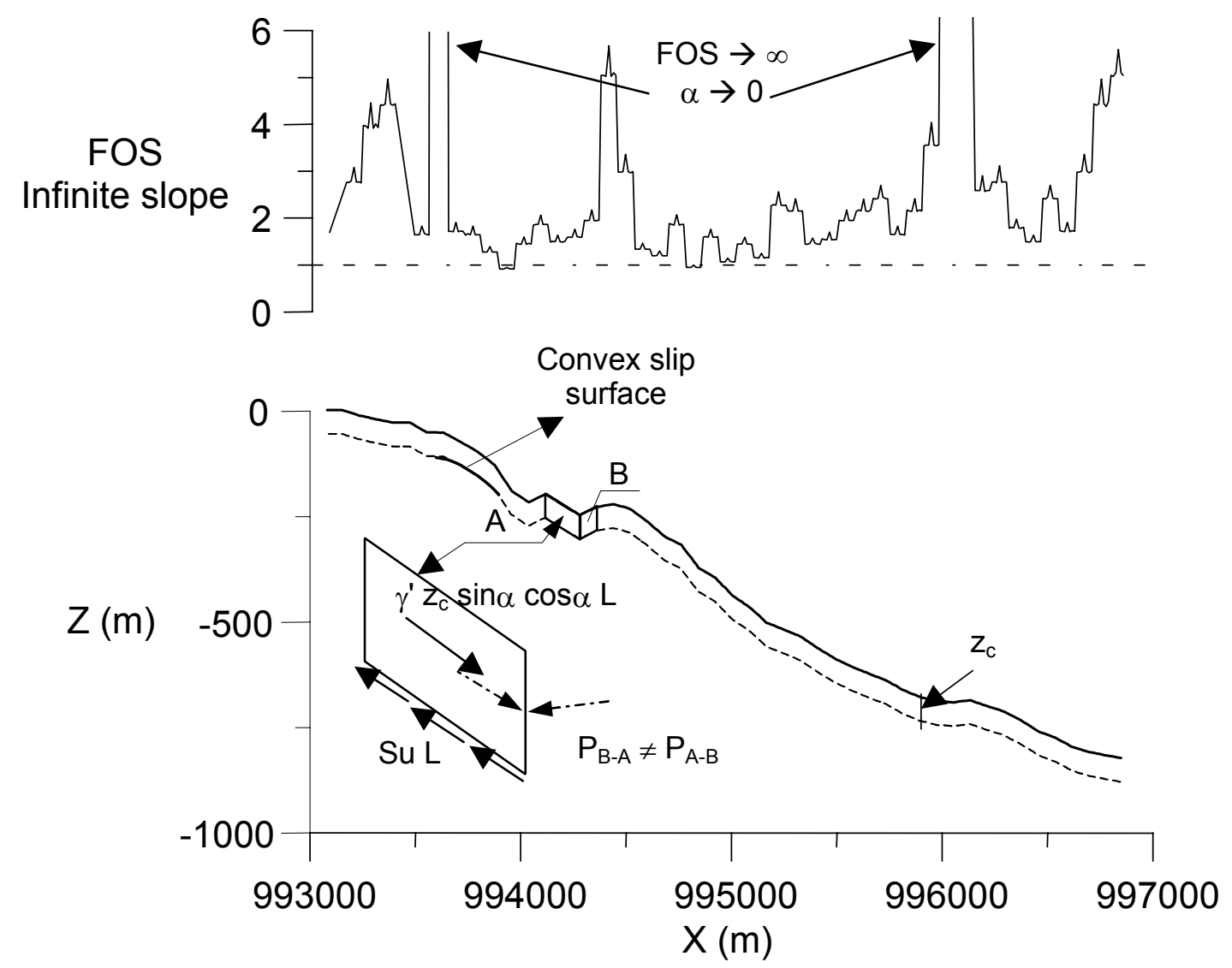

Figure 16. Infinite slope stability. 


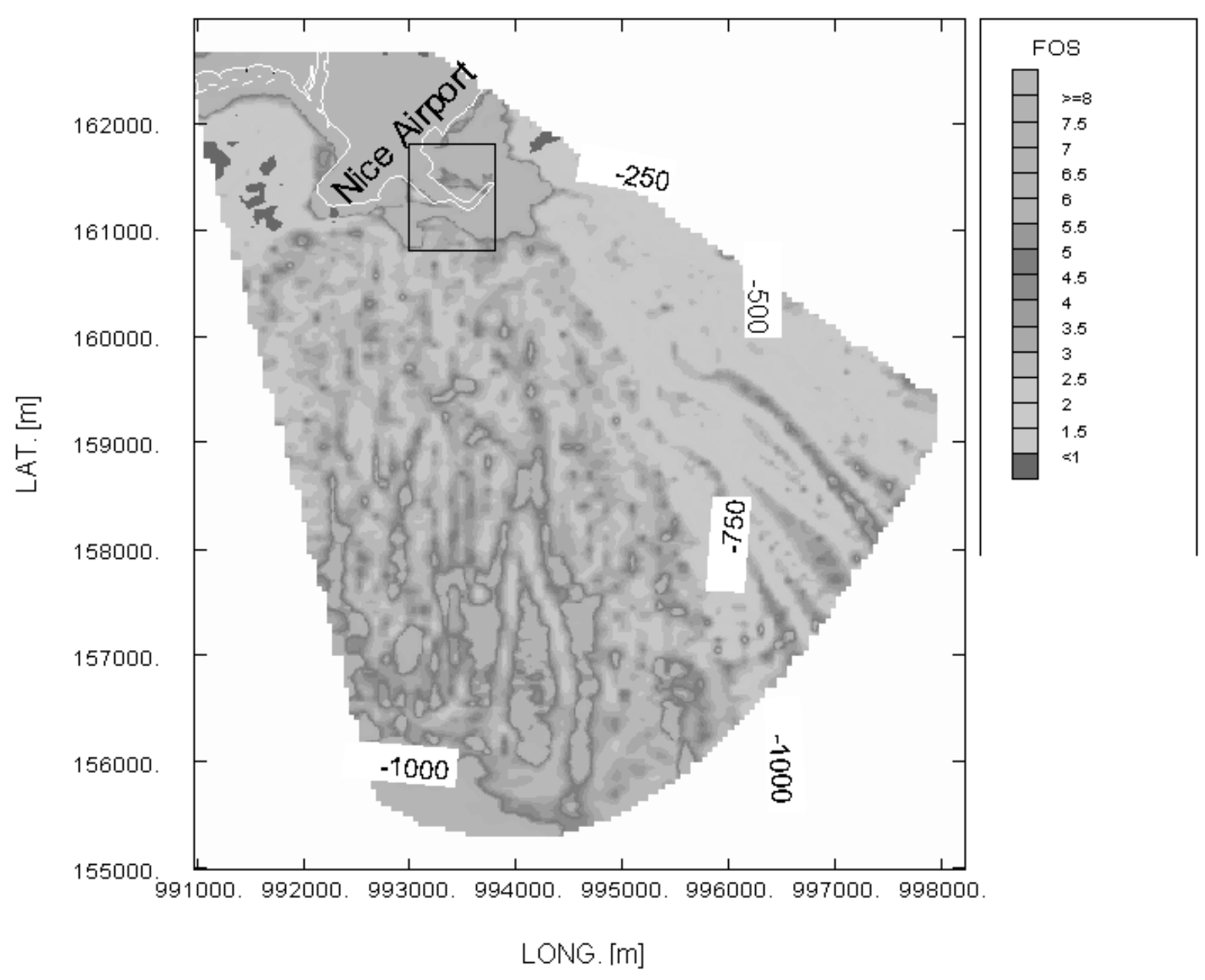

Figure 17. Safety factor map from an infinite slope analysis. 


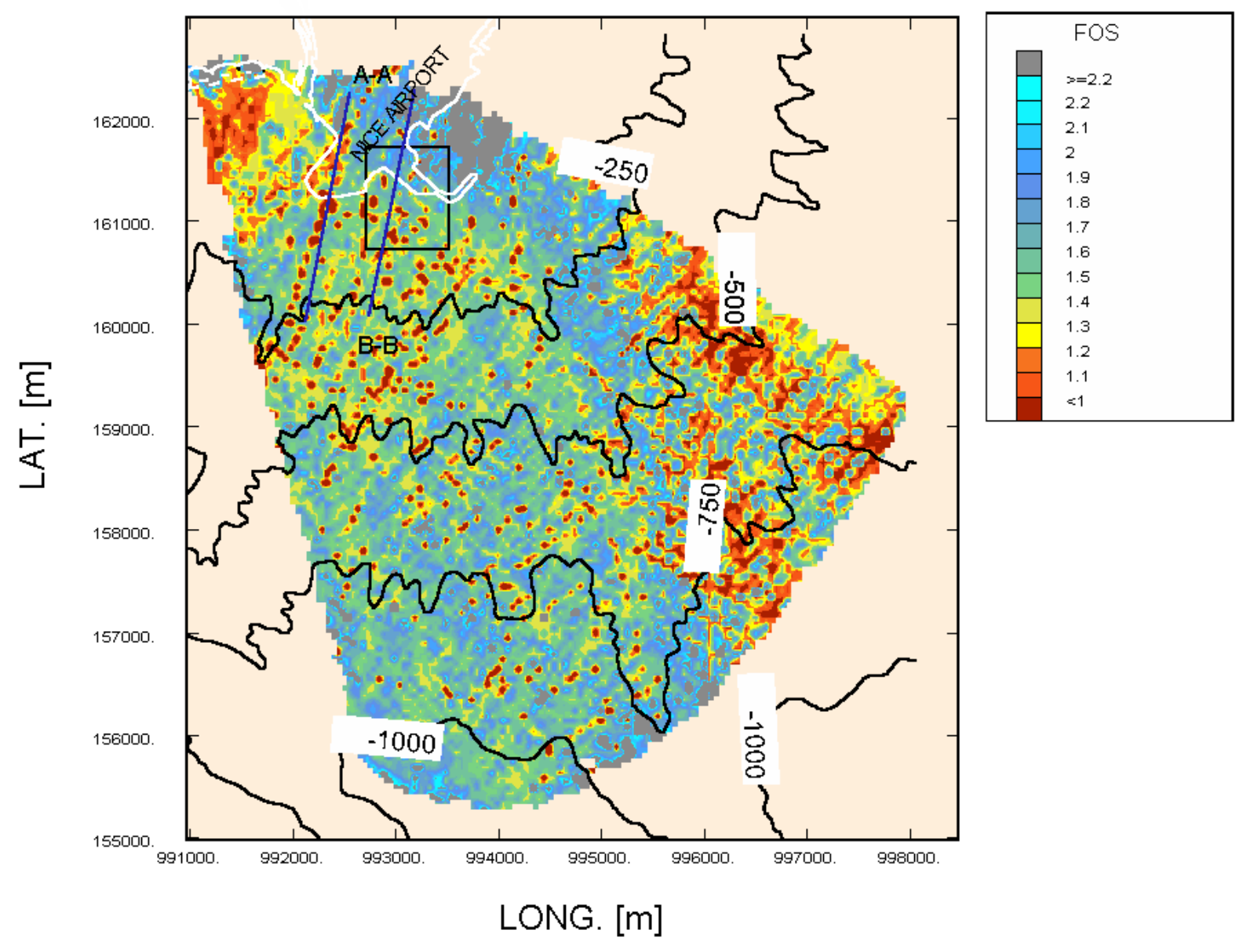

Figure 18. Safety factor map from a generalised limit equilibrium method. 


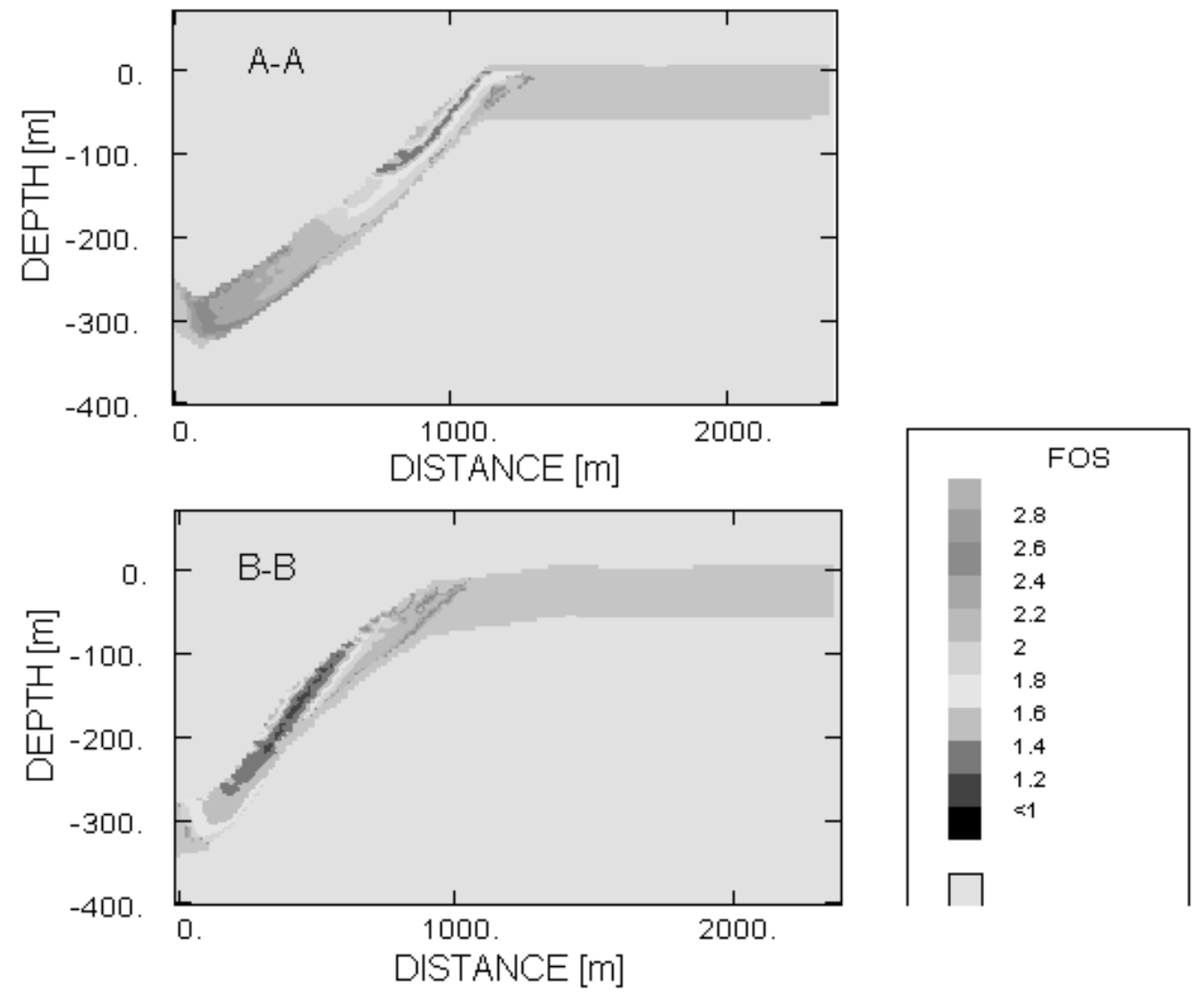

Figure 19. Equal values of the factor of safety along a) the A-A cross-section and b) the B-B cross-section. 


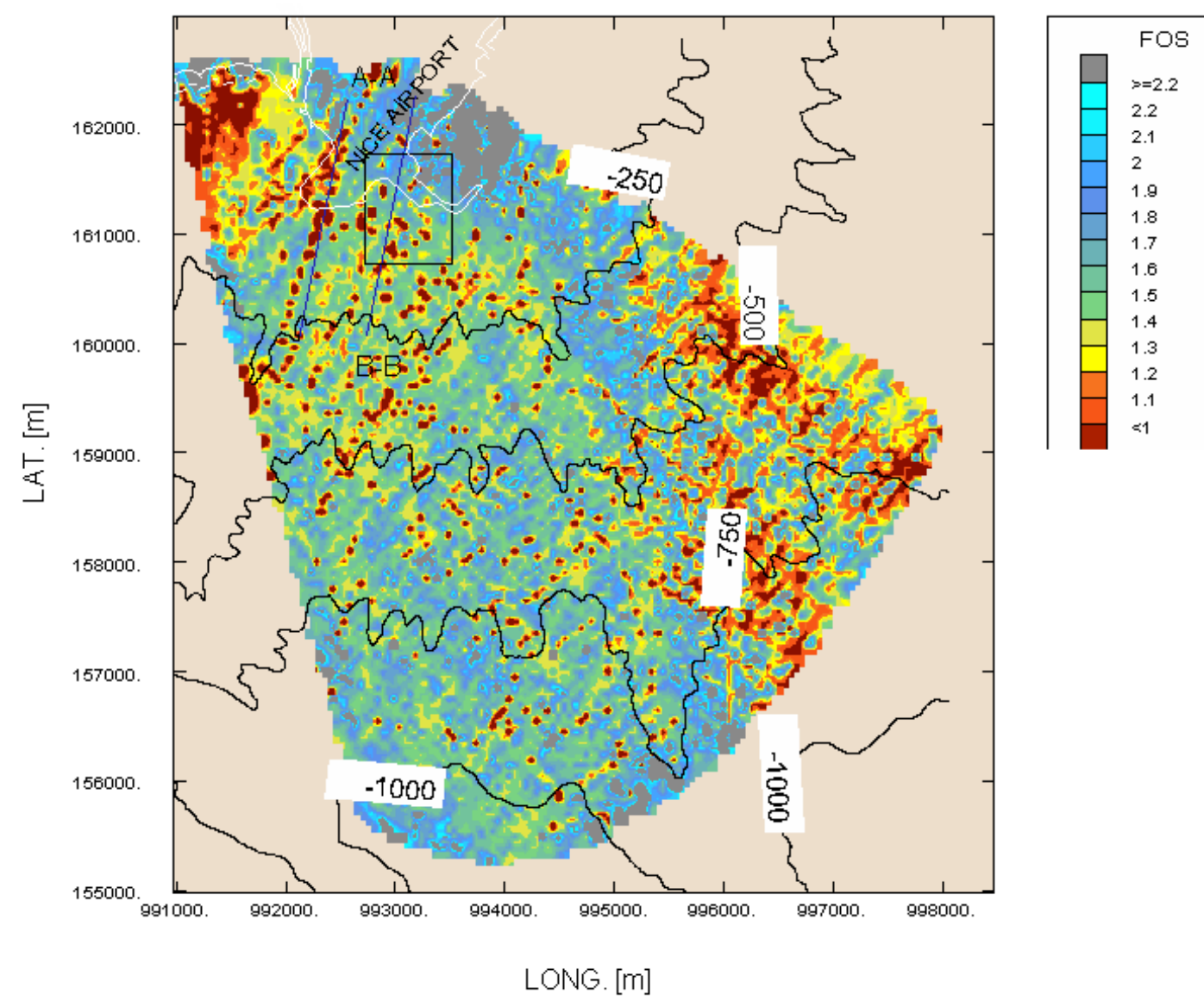

Figure 20. Safety factor map from a generalised limit equilibrium method using Seed's scenario. 


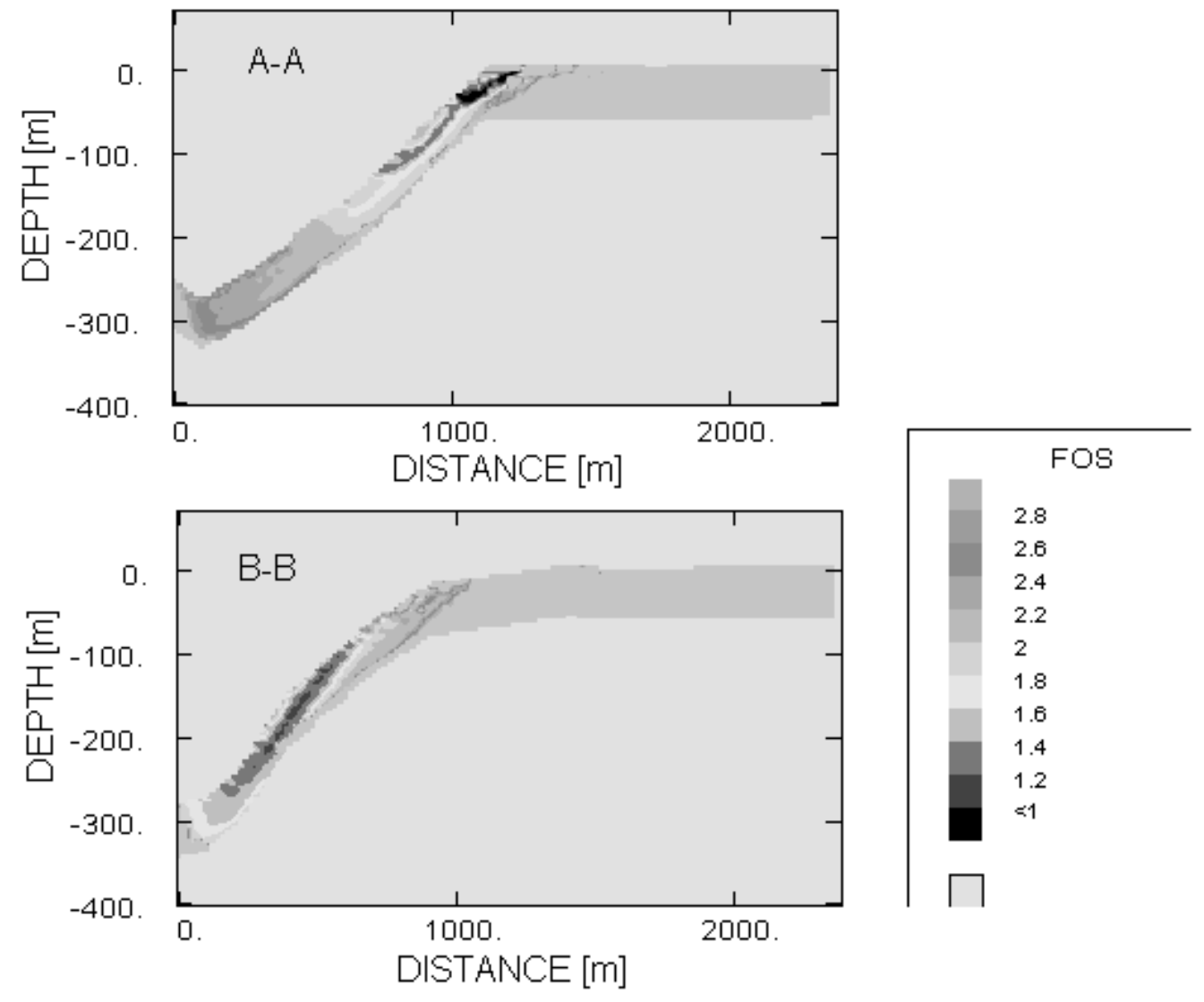

Figure 21. Equal values of the factor of safety along a) the A-A cross-section and b) the B-B cross-section using Seed's scenario. 


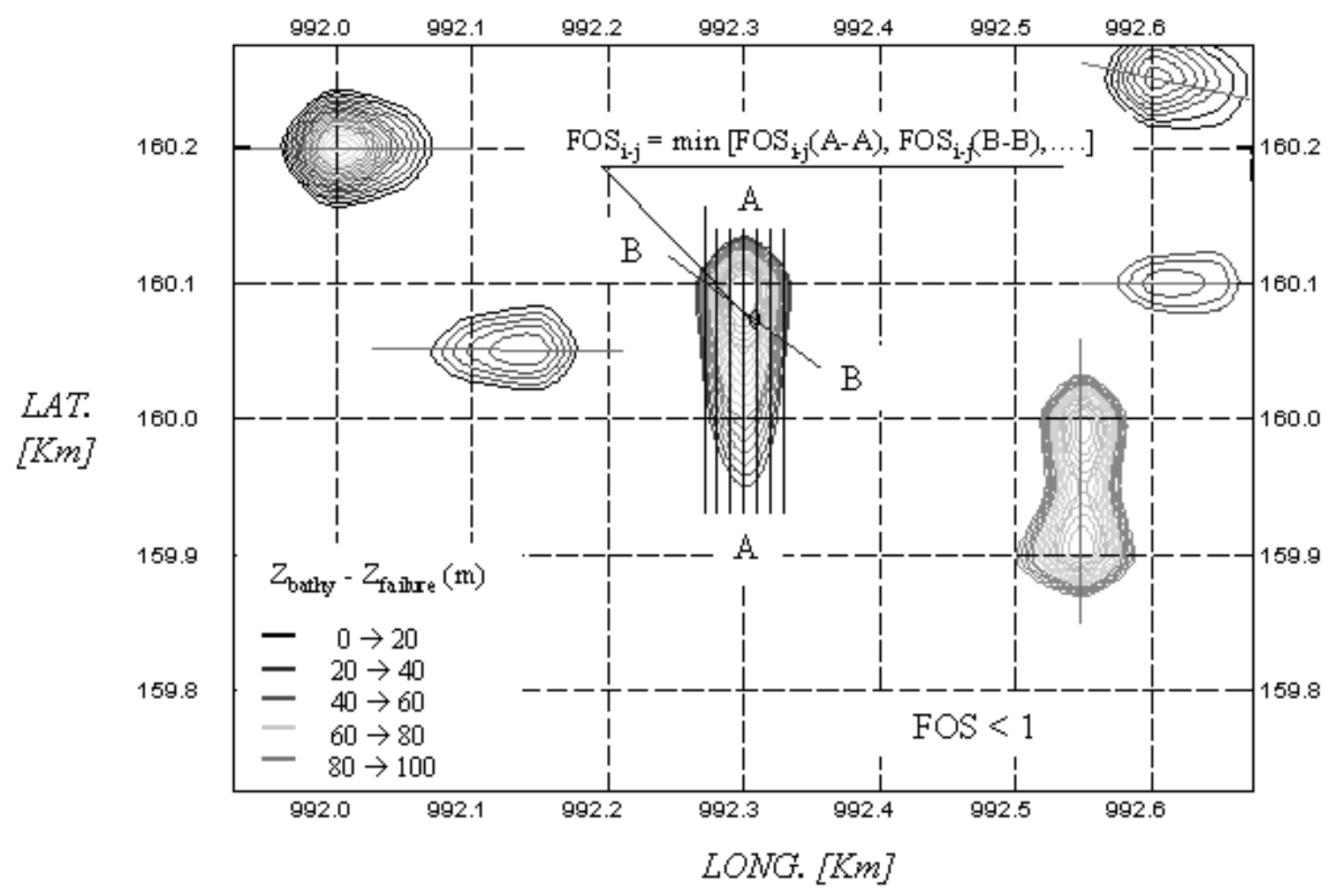

Figure 22. Approximate three-dimensional reconstruction of the failure surface. 
